\section{Histoire Épistémologie Langage}

43-1 | 2021

La grammaire grecque étendue

\title{
Ueber die Buchstabenschrift und ihren Zusammenhang mit dem Sprachbau
}

Sur l'écriture alphabétique et son rapport avec la structure de la langue

\section{Wilhelm von Humboldt}

Traducteur : Lucie Bourassa

\section{OpenEdition}

\section{Journals}

Édition électronique

URL : https://journals.openedition.org/hel/699

DOI : $10.4000 /$ hel.699

ISSN : 1638-1580

Éditeur

Société d'histoire et d'épistémologie des sciences du langage

\section{Édition imprimée}

Date de publication : 30 juin 2021

Pagination : 122-167

ISBN : 9791091587143

ISSN : 0750-8069

Référence électronique

Wilhelm von Humboldt, « Ueber die Buchstabenschrift und ihren Zusammenhang mit dem Sprachbau », Histoire Épistémologie Langage [En ligne], 43-1 | 2021, mis en ligne le 28 octobre 2021, consulté le 29 octobre 2021. URL : http://journals.openedition.org/hel/699 ; DOI : https://doi.org/ 10.4000/hel.699

\section{(c) (i) (9)}

HEL is licensed under a Creative Commons Attribution-NonCommercial-NoDerivatives 4.0 International License 


\title{
UEBER DIE BUCHSTABENSCHRIFT UND IHREN ZUSAMMENHANG MIT DEM SPRACHBAU
}

\author{
Wilhelm von Humboldt
}

1- [107] Es hat mir bei dem Nachdenken über den Zusammenhang der Buchstabenschrift mit der Sprache immer geschienen, als wenn die erstere in genauem Verhältniss mit den Vorzügen der letzteren stände, und als wenn die Annahme und Bearbeitung des Alphabets, ja selbst die Art und vielleicht auch die Erfindung desselben, von dem Grade der Vollkommenheit der Sprache, und noch ursprünglicher, der Sprachanlagen jeder Nation abhienge*.

2- Anhaltende Beschäftigung mit den Amerikanischen Sprachen, Studium der Alt-Indischen und einiger mit ihr verwandten, und die Betrachtung des Baues der Chinesischen schienen mir diesen Satz auch geschichtlich zu bestätigen. Die Amerikanischen Sprachen, die man zwar sehr mit Unrecht mit dem Namen roher und wilder bezeichnen würde, die aber ihr Bau doch bestimmt von den vollkommen gebildeten unterscheidet, haben, soviel wir bis jetzt wissen, nie Buchstabenschrift besessen. Mit den Semitischen und der Indischen ist diese so innig verwachsen, dass auch nicht die entfernteste Spur vorhanden ist, dass sie sich jemals einer andren bedient hätten. Wenn die Chinesen beharrlich die ihnen seit so langer Zeit bekannten Alphabete der Europaeer zurückstossen, so liegt dies, meines Erachtens, bei weitem nicht bloss in ihrer An- / [108] hänglichkeit am Hergebrachten, und ihrer Abneigung gegen das Fremde, sondern viel mehr darin, dass, nach dem Mass ihrer Sprachanlagen, und nach dem Bau ihrer Sprache, noch gar nicht das innere Bedürfniss nach einer Buchstabenschrift in ihnen erwacht ist. Wäre dies nicht der Fall, so würden sie durch ihre eigene, ihnen in hohem Grade beiwohnende Erfindsamkeit, und durch ihre Schriftzeichen selbst dahin gekommen seyn, nicht bloss, wie sie jetzt thun, Lautzeichen als Nebenhülfe zu gebrauchen, sondern ein wahres, vollständiges und reines Alphabet zu bilden.

* Le texte allemand est reproduit d'après l'édition suivante : Humboldt, Wilhelm von. 1906. Gesammelte Schriften, vol. V, 107-133. Éd. par Albert Leitzmann, Wilhelm Richter \& Bruno Gebhardt avec la participation de Siegfried Kähler \& Eduard Spranger. Berlin : Behr. Les numéros de pages dans le texte renvoient à cette édition. La numérotation des paragraphes a été ajoutée par nous. 


\title{
SUR L'ÉCRITURE ALPHABÉTIQUE ET SON RAPPORT AVEC LA STRUCTURE DE LA LANGUE
}

\author{
Wilhelm von Humboldt
}

Traduction : Lucie Bourassa

1- [V, 107] Au cours de ma réflexion sur le rapport de l'écriture alphabétique avec la langue, il m'a toujours semblé que la première était en relation exacte avec les avantages de la seconde, et que l'adoption et l'élaboration de l'alphabet, voire la sorte d'alphabet et peut-être aussi son invention, dépendaient du degré de perfection de la langue et, plus originairement, des dispositions linguistiques de chaque nation. ${ }^{1}$

2- Une réflexion de longue durée sur les langues américaines, l'étude du vieilindien et de quelques langues de la même famille, ainsi que l'observation de la structure du chinois m'ont semblé apporter une confirmation historique à cette thèse. Les langues américaines, que l'on qualifierait certes à tort de plus brutes et de plus sauvages, mais dont la structure se distingue quand même nettement de celle des langues parfaitement cultivées, n'ont, autant que nous le sachions pour le moment, jamais possédé d'écriture alphabétique. Celle-ci est par contre si étroitement liée aux langues sémitiques et indienne qu'on ne peut trouver même la trace la plus lointaine de ce que ces langues aient jamais eu recours à une autre forme d'écriture. Si les Chinois rejettent obstinément l'alphabet des Européens, qu'ils connaissent pourtant depuis si longtemps, à mon avis cela ne tient pas, loin s'en faut, à leur seul [V, 108] attachement à la tradition, ni à leur aversion pour ce qui est étranger, mais bien plutôt au fait que, en fonction de leurs dispositions linguistiques et étant donnée la structure de leur langue, ils n'ont jamais éprouvé de l'intérieur le besoin d'une écriture alphabétique. Si ce n'était pas le cas, ils ne se contenteraient pas, ainsi qu'ils le font maintenant, d'utiliser les signes phonétiques comme une ressource auxiliaire, mais ils auraient d'eux-mêmes été amenés à créer, à l'aide de la très grande inventivité qui les habite et de leurs signes d'écriture, un alphabet véritable, pur et complet. 
3- Auf Aegypten allein schien diese Vorstellungsart nicht recht zu passen. Denn die heutige Coptische Sprache beweist unläugbar, dass auch die Alt-Aegyptische einen Bau besass, der nicht von grossen Sprachanlagen der Nation zeugt, und dennoch hat Aegypten nicht nur Buchstabenschrift besessen, sondern war sogar, nach keinesweges verwerflichen Zeugnissen, die Wiege derselben. Allein auch wenn eine Nation Erfinderin einer Buchstabenschrift ist, bleibt ihre Art, dieselbe zu behandeln, ihrer Anlage entsprechend, den Gedanken aufzufassen, und durch Sprache zu fesseln und auszubilden; und die Wahrheit dieser Behauptung leuchtet gerade recht aus der wunderbaren Art hervor, wie die Aegyptier Bilder- und Buchstabenschrift in einander übergehen liessen.

4- Buchstabenschrift und Sprachanlage stehen daher in dem engsten Zusammenhange, und in durchgängiger Beziehung auf einander. Dies werde ich mich bemühen, hier sowohl aus Begriffen, als, soviel es in der Kürze geschehen kann, welche diesen Abhandlungen geziemt, geschichtlich zu beweisen. Die Wahl dieses Gegenstandes hat mir aus dem zwiefachen Grunde angemessen geschienen, dass die Natur der Sprache in der That nicht vollständig eingesehen werden kann, wenn man nicht zugleich ihren Zusammenhang mit der Buchstabenschrift untersucht, und dass gerade jene neuesten Beschäftigungen mit der Aegyptischen Schrift den Antheil an Untersuchungen über Schrift-Erfindung und Aneignung im gegenwärtigen Augenblicke verdoppeln.

5- Alles, was sich auf die äussren Zwecke der Schrift, ihren Nutzen im Gebrauch für das Leben und die Verbreitung der Kenntnisse bezieht, übergehe ich gänzlich. Ihre Wichtigkeit von dieser Seite leuchtet zu sehr von selbst ein, und nur Wenige dürften in dieser Hinsicht die Vorzüge der Buchstabenschrift vor den übrigen Schriftarten verkennen. Ich beschränke mich bloss auf den Einfluss der alphabetischen auf die Sprache und ihre [109] Behandlung. Ist dieser wirklich bedeutend, ist der Zusammenhang der Sprache mit dem Gebrauche eines Alphabets innig und fest, so können auch die Ursachen begieriger Aneignung der Buchstabenschrift, oder kalter Gleichgültigkeit gegen dieselbe nicht länger zweifelhaft bleiben.

6- Wie aber schon oft von den Sprachen selbst behauptet wird, dass ihre Verschiedenheit nicht von grosser Wichtigkeit sey, da, wie auch der Schall laute, und die Rede sich verknüpfe, doch endlich immer derselbe Gedanke hervortrete, so dürfte die Art der Schriftzeichen noch für bei weitem gleichgültiger gehalten werden, wenn sie nur nicht gar zu grosse Unbequemlichkeit mit sich führe, oder die Nation sich gewöhnt habe, die mit ihr verbundnen zu überwinden. Auch machen diejenigen, welche sich der Schrift häufig, und noch weit mehr diejenigen, welche sich derselben auf eine sinnige Weise bedienen, immer nur von jedem Volke einen kleinen Theil aus. Jede Sprache hat also nicht bloss lange Zeit ohne Schrift bestanden, sondern lebt auch grossentheils beständig auf gleiche Art fort.

7- Allein das tönende Wort ist gleichsam eine Verkörperung des Gedanken, die Schrift eine des Tons. Ihre allgemeinste Wirkung ist, dass sie die Sprache fest heftet, und dadurch ein ganz andres Nachdenken über dieselbe möglich macht, 
3- Cette façon de voir cependant semblait ne pas bien s'appliquer à l'Égypte. Car la langue copte d'aujourd'hui prouve indéniablement que la structure du vieilégyptien ne manifestait pas, dans la nation qui le parlait, de grandes dispositions linguistiques, et pourtant, l'Égypte non seulement possédait l'écriture alphabétique, mais elle en était même, comme le montrent des preuves qu'on ne peut pas du tout rejeter, le berceau. Cependant, même quand une nation est l'inventrice d'une écriture alphabétique, elle maintient sa manière de traiter celle-ci selon sa disposition, pour saisir la pensée, puis pour la fixer et la développer par la langue ; et la vérité de cette assertion ressort précisément de la merveilleuse manière dont les Égyptiens ont laissé l'écriture en images et l'écriture alphabétique se fondre l'une dans l'autre.

4- L'écriture alphabétique et les dispositions linguistiques sont par conséquent en rapport très étroit et en constante interaction. Je vais m'efforcer ici de montrer cela avec des concepts, mais aussi, pour autant que cela convienne à la brièveté des présents mémoires, historiquement. Le choix de cet objet m'est apparu pertinent pour deux raisons, d'abord parce que la nature de la langue ne peut, dans les faits, être comprise intégralement si on n'examine pas en même temps son rapport avec l'écriture alphabétique, ensuite parce que, justement, les études les plus récentes sur l'écriture égyptienne ${ }^{2}$ redoublent en ce moment l'intérêt pour les recherches sur l'invention et l'appropriation de l'écriture.

5- Je laisse complètement de côté tout ce qui concerne les buts extérieurs de l'écriture, soit l'utilité de son emploi dans la vie et dans la diffusion de la connaissance. Son importance sur ce plan est trop évidente en elle-même et seuls quelques-uns doivent méconnaître, sur ce point, les avantages de l'écriture alphabétique face aux autres genres d'écriture. Je me limite simplement à l'influence de l'alphabet sur la langue et son $[\mathrm{V}, 109]$ traitement. Si cette influence est vraiment significative, si le rapport de la langue avec l'usage d'un alphabet est intime et solide, les causes de l'avide appropriation de l'écriture alphabétique ou de la froide indifférence à son égard ne peuvent demeurer plus longtemps incertaines.

6- Mais combien de fois a-t-on entendu affirmer, au sujet des langues ellesmêmes, que leur diversité ne serait pas d'une grande importance, parce que, quelle que soit la manière dont le son s'énonce, et dont le discours se noue, c'est toujours la même pensée finalement qui apparaît, de sorte que le genre de signes d'écriture devrait être tenu pour d'autant plus indifférent ${ }^{3}$, tant qu'il n'entraîne pas trop d'incommodité ou que la nation s'est habituée à surmonter celle qui lui est liée. Aussi, ceux qui se servent souvent de l'écriture, et encore plus, ceux qui s'en servent d'une manière judicieuse, ne constituent qu'une faible partie de chaque peuple. Chaque langue a ainsi non seulement vécu longtemps sans écriture, mais continue aussi à survivre durablement en grande partie de cette manière.

7- Cependant, le mot sonore est pour ainsi dire une incarnation de la pensée, l'écriture une incarnation du son. L'action la plus générale de l'écriture est de fixer durablement la langue et ainsi de rendre possible à son sujet une réflexion 
als wenn das verhallende Wort bloss im Gedächtniss eine bleibende Stätte findet. Es ist aber auch zugleich unvermeidlich, dass sich nicht irgend eine Wirkung dieser Bezeichnung durch Schrift, und der bestimmten Art derselben überhaupt dem Einflusse der Sprache auf den Geist beimischen sollte. Es ist daher keinesweges gleichgültig, welche Art der Anregung die geistige Thätigkeit durch die besondre Natur der Schriftbezeichnung erhält. Es liegt in den Gesetzen dieser Thätigkeit, das Denkbare und Anschauliche als Zeichen und Bezeichnetes zu betrachten, wechselsweise hervorzurufen, und in verschiedne Stellung gegen einander zu bringen; es ist ihr eigen, bei einer Idee oder Anschauung auch die verwandten wirken zu lassen, und so kann die Uebertragung des erst als Ton gehefteten Gedanken auf einen Gegenstand des Auges, nach Massgabe der Art, wie sie geschieht, dem Geiste sehr verschiedne Richtungen geben. Offenbar aber müssen, wenn die Gesammtwirkung nicht gestört werden soll, das Denken in Sprache, die Rede und die Schrift übereinstimmend gebildet, und wie aus Einer Form gegossen seyn./

8- [V, 110] Darum dass die Schrift nur immer Eigenthum eines kleineren Theils der Nation bleibt, und wohl überall erst entstanden ist, als der schon festbestimmte Sprachbau nicht mehr wesentliche Umänderungen zuliess, ist ihr Einfluss auf sie nicht minder wichtig. Denn die gemeinschaftliche Rede umschlingt doch (freilich in einer Lebensform weniger, als in der andren) das ganze Volk, und was auf sie bei Einzelnen gewirkt ist, geht doch mittelbar auf Alle über. Die feinere Bearbeitung der Sprache aber, für welche der Gebrauch der Schrift eigentlich erst den Anfangspunkt bezeichnet, ist gerade die wichtigste, und unterscheidet, an sich und in ihrer Wirkung auf die Nationalbildung, die Eigenthümlichkeit der Sprachen bei weitem mehr, als der gröbere, ursprüngliche Bau.

9- Die Eigenthümlichkeit der Sprache besteht darin, dass sie, vermittelnd, zwischen dem Menschen und den äussren Gegenständen eine Gedankenwelt an Töne heftet. Alle Eigenschaften jeder einzelnen können daher auf die beiden grossen Hauptpunkte in der Sprache überhaupt bezogen werden, ihre Idealität und ihr Tonsystem. Was der ersteren an Vollständigkeit, Klarheit, Bestimmtheit und Reinheit, dem letzteren an Vollkommenheit abgeht, sind ihre Mängel, das Entgegengesetzte ihre Vorzüge.

10- Diese Ansicht habe ich in zwei, dieser Versammlung früher vorgelegten Abhandlungen aufzustellen und zu rechtfertigen versucht, und mich bemühet zu zeigen:

- dass das, auch unverknüpfte Wortsystem jeder Sprache eine Gedankenwelt bildet, die, gänzlich heraustretend aus dem Gebiet willkührlicher Zeichen, für sich Wesenheit und Selbständigkeit besitzt;

- dass diese Wortsysteme niemals einem einzelnen Volk allein angehören, sondern auf einem Wege der Ueberlieferung, den weder die Geschichte, noch die Sprachforschung ganz zu verfolgen im Stande sind, zu dem Werke der gesammten Menschheit alle Jahrhunderte ihres Daseyns hindurch werden, und dass mithin jedes Wort ein doppeltes Bildungselement in sich trägt, ein 
tout à fait différente de celle qu'autorise le mot évanescent, dont la mémoire est la seule demeure. Mais il est aussi inévitable que l'effet peu ordinaire de la désignation par l'écriture et celui du genre déterminé d'écriture s'ajoutent à l'influence de la langue sur l'esprit. Par conséquent, la forme de stimulation que reçoit l'activité spirituelle ${ }^{4}$ selon la nature particulière de la désignation par l'écriture n'est pas du tout indifférente. Cela appartient aux lois de cette activité de considérer le pensable et le sensible comme signe et comme signifié, de les susciter alternativement et de les confronter dans des positions variées ; cela lui est propre, à l'occasion d'une idée ou d'une intuition, de laisser aussi agir celles qui sont apparentées, si bien que le transfert à un objet visible de la pensée d'abord fixée en tant que son peut donner à l'esprit des directions fort différentes, suivant la manière dont elle se produit. Mais de toute évidence, si l'effet d'ensemble ne doit pas être perturbé, il faut que l'acte de penser en langage, le discours et l'écriture soient formés de manière concordante et comme fondus à partir du même moule.

8- [V, 110] Parce que l'écriture demeure toujours le bien d'une petite partie seulement de la nation et n'est sans doute née en tous lieux que lorsque la structure de la langue, déjà bien fixée, ne permettait plus de transformations substantielles, son influence sur celle-ci n'en est pas moins importante. Car la parole commune embrasse quand même le peuple entier (bien sûr moins dans un mode d'existence que dans l'autre) et l'action qu'ont sur elle quelques individus se transmet indirectement à tous. Mais l'élaboration la plus fine de la langue, dont l'usage de l'écriture ne marque en fait que le point de départ, est précisément le plus important et détermine, en elle-même et par son action sur la culture nationale, la particularité d'une langue, beaucoup plus que la structure originelle, plus grossière ${ }^{5}$.

9- La particularité de la langue réside dans le fait que, médiatrice entre l'homme et les objets extérieurs, elle attache un monde de pensées à des sons. Toutes les propriétés des langues individuelles peuvent par conséquent être rapportées aux deux facettes essentielles de la langue en général, son idéalité et son système de sons. Ce qui fait défaut à la première en complétude, en clarté, en définition et en pureté, au dernier en perfection, sont leurs manques et l'opposé leurs avantages.

10- J'ai tenté d'exposer et de justifier ce point de vue dans deux mémoires ${ }^{6}$ présentés plus tôt devant cette assemblée, en m'efforçant demontrer :

- que le système des mots de toutes les langues, même hors des enchaînements, forme un monde de pensées qui, sortant entièrement du domaine des signes arbitraires, possède en lui-même sa nature et son autonomie ;

- que ces systèmes de mots n'appartiennent jamais à un seul peuple isolé, mais qu'ils deviennent l'œuvre que l'humanité entière a façonnée au cours de tous les siècles de son existence, au moyen d'une sorte de tradition que ni l'histoire ni la recherche sur le langage ne sont en état de reconstituer entièrement, et que par conséquent chaque mot porte en lui-même un double élément formateur, un 
physiologisches, aus der Natur des menschlichen Geistes hervorgehendes, und ein geschichtliches, in der Art seiner Entstehung liegendes; ferner:

- dass der Charakter der vollkommner gebildeten Sprachen dadurch bestimmt wird, dass die Natur ihres Baues beweist, dass / [111] es dem Geist nicht bloss auf den Inhalt, sondern vorzüglich auf die Form des Gedanken ankommt.

11- Ich glaube diesen Weg auch hier verfolgen zu können, und es leuchtet nun von selbst ein, dass die Buchstabenschrift die Idealität der Sprache schon insofern negativ befördert, als sie den Geist auf keine, von der Form der Sprache abweichende Weise anregt, dass aber das Tonsystem, da Lautbezeichnung ihr Wesen ausmacht, erst durch sie Festigkeit und Vollständigkeit erlangen kann.

12- Dass jede Bilderschrift durch Anregung der Anschauung des wirklichen Gegenstandes die Wirkung der Sprache stören muss, statt sie zu unterstützen, fällt von selbst in die Augen. Die Sprache verlangt auch Anschauung, heftet sie aber an die, vermittelst des Tones, gebundene Wortform. Dieser muss sich die Vorstellung des Gegenstandes unterordnen, um als Glied zu der unendlichen Kette zu gehören, an welcher sich das Denken durch Sprache nach allen Richtungen hinschlingt. Wenn sich das Bild zum Schriftzeichen aufwirft, so drängt es unwillkührlich dasjenige zurück, was es bezeichnen will, das Wort. Die Herrschaft der Subjectivität, das Wesen der Sprache, wird geschwächt, die Idealität dieser leidet durch die reale Macht der Erscheinung, der Gegenstand wirkt nach allen seinen Beschaffenheiten auf den Geist, nicht nach denjenigen, welche das Wort, in Uebereinstimmung mit dem individuellen Geiste der Sprache, auswählend zusammenfasst, die Schrift, die nur Zeichen des Zeichens seyn soll, wird zugleich Zeichen des Gegenstandes, und schwächt, indem sie seine unmittelbare Erscheinung in das Denken einführt, die Wirkung, welche das Wort gerade dadurch ausübt, dass es nur Zeichen seyn will. An Lebendigkeit kann die Sprache durch das Bild nicht gewinnen, da diese Gattung der Lebendigkeit nicht ihrer Natur entspricht, und die beiden verschiednen Thätigkeiten der Seele, die man hier zugleich anregen möchte, können nicht Verstärkung, sondern nur Zerstreuung der Wirkung zur Folge haben.

13- Dagegen scheint eine Figurenschrift, welche Begriffe bezeichnet, recht eigentlich die Idealität der Sprache zu befördern. Denn ihre willkührlich gewählten Zeichen haben ebensowenig, als die der Buchstaben, etwas, das den Geist zu zerstreuen vermöchte, und die innere Gesetzmässigkeit ihrer Bildung führt das Denken auf sich selbst zurück.

14- Dennoch wirkt auch eine solche Schrift gerade der idealen, / [112] d.h. der die Aussenwelt in Ideen verwandelnden Natur der Sprache entgegen, wenn sie auch nach der strengsten Gesetzmässigkeit in allen ihren Theilen zusammengefügt wäre. Denn für die Sprache ist nicht bloss die sinnliche Erscheinung stoffartig, sondern auch das unbestimmte Denken, inwiefern es nicht fest und rein durch den Ton gebunden ist; denn es ermangelt der ihr wesentlich eigenthümlichen Form. Die Individualität der Wörter, in deren jedem immer noch etwas andres, als bloss seine logische Definition liegt, ist insofern an den Ton geheftet, als durch diesen unmittelbar in der Seele die ihnen eigenthümliche 
élément physiologique, issu de la nature de l'esprit humain, et un élément historique, qui réside dans le mode de sa genèse ; en outre,

- que le caractère des langues parfaitement cultivées est déterminé par le fait que ce qui importe à l'esprit, comme la nature de leur structure le prouve, [V, 111] ce n'est pas simplement le contenu, mais d'abord la forme de la pensée.

11- Je crois pouvoir poursuivre ici dans cette voie et il est à présent évident que l'écriture alphabétique favorise bien l'idéalité de la langue, de manière négative, dans la mesure où elle empêche l'esprit de s'écarter de la forme de la langue, cependant que le système de sons - puisque la désignation par les sons constitue l'essence de la langue - ne peut acquérir sa stabilité et sa complétude qu'à l'aide d'une telle désignation.

12- Cela saute aux yeux que toute écriture en images, en éveillant l'intuition de l'objet réel, perturbe nécessairement l'action de la langue au lieu de la faciliter. La langue sollicite aussi cette intuition, mais elle l'attache, au moyen des sons, à la forme liée du mot. Le son doit se subordonner la représentation de l'objet afin de devenir un maillon de la chaîne infinie à laquelle s'enlace dans toutes les directions l'activité de penser par le langage Quand l'image se pose en signe d'écriture, elle refoule involontairement ce qu'elle veut désigner, le mot. Le règne de la subjectivité, l'essence du langage, en est affaibli, l'idéalité du langage souffre par la force concrète de l'apparence, l'objet agit sur l'esprit selon toutes ses propriétés et non selon les propriétés que le mot, en accord avec l'esprit individuel de la langue, élit et rassemble ; l'écriture, qui doit n'être que signe du signe, devient en même temps signe de l'objet et affaiblit, en ce qu'elle introduit l'apparence immédiate de l'objet dans la pensée, l'action que le mot exerce précisément du fait même qu'il ne veut être qu'un signe. La langue ne peut pas gagner en vivacité grâce à l'image, parce que ce type de vivacité ne correspond pas à sa nature et que les deux activités différentes de l'âme que l'on voudrait éveiller ici en même temps ne peuvent pas avoir pour conséquence un renforcement, mais seulement une dispersion de l'action du langage.

13- Par contre une écriture en figures ${ }^{7}$, qui désigne des concepts, semble bien justement favoriser l'idéalité de la langue. En effet, ses signes arbitrairement choisis ont, aussi peu que les signes alphabétiques, de quoi distraire l'esprit, et la légalité ${ }^{8}$ interne de leur formation ramène la pensée à elle-même.

14- Néanmoins, une telle écriture, $[\mathrm{V}, 112]$ quand bien même elle serait dans toutes ses parties assemblée selon la légalité la plus stricte, agit précisément elle aussi contre la nature idéale de la langue, celle qui consiste à transformer le monde extérieur en idées. Car ce ne sont pas seulement les phénomènes sensibles qui constituent le matériau de la langue, mais aussi l'activité de penser, qui reste indéterminée tant qu'elle n'est pas fixée de manière stable et nette par le son; car manque la forme qui lui est particulière par essence. L'individualité des mots, en vertu de laquelle chacun est toujours quelque chose d'autre que sa simple définition logique, est attachée au son, dans la mesure où ce dernier éveille directement dans l'âme leur effet particulier. Un signe qui recherche le 
Wirkung geweckt wird. Ein Zeichen, das den Begriff aufsucht, und den Ton vernachlässigt, kann sie mithin nur unvollkommen ausdrücken. Ein System solcher Zeichen giebt nur die abgezognen Begriffe der äussren und innren Welt wieder; die Sprache aber soll diese Welt selbst zwar in Gedankenzeichen verwandelt, aber in der ganzen Fülle ihrer reichen, bunten und lebendigen Mannigfaltigkeit enthalten.

15- Es hat aber auch nie eine Begriffsschrift gegeben, und kann keine geben, die rein nach Begriffen gebildet wäre, und auf die nicht die in bestimmte Laute gefassten Wörter der Sprache, für welche sie erfunden wurde, den hauptsächlichsten Einfluss ausgeübt hätten. Denn da die Sprache doch vor der Schrift da ist, so sucht dieselbe natürlich für jedes Wort ein Zeichen, und nimmt diese, wenn sie auch durch systematische Unterordnung unter ein Begriffssystem vom Laut unabhängige Geltung hätten, doch in dem Sinn der ihnen untergelegten Wörter. Daher ist jede Begriffsschrift immer zugleich eine Lautschrift und ob sie, nebenher und in welchem Grade, auch als wahre Begriffsschrift gilt? hängt von dem Grade ab, in welchem der sie Gebrauchende die systematische Unterordnung ihrer Zeichen, den logischen Schlüssel ihrer Bildung kennt und beachtet. Wer die den Wörtern entsprechenden Zeichen nur mechanisch kennt, besitzt in ihr nichts, als eine Lautschrift. Wenn eine solche Schrift auf eine andre Sprache übergeht, findet der gleiche Fall statt. Denn auch in dieser muss der Gebrauch, wenn die Schrift wirklich Schrift seyn soll, doch jedem Zeichen seine Geltung in Einem, oder mehreren bestimmten Wörtern anweisen. Die Schriftzeichen sind also in beiden Sprachen nur insofern gleichbedeutend, als es die ihnen untergelegten Wörter sind, und das Lesen des in einer beider Sprachen Geschriebnen wird für den dieser Sprache Unkundigen immer zu einem Uebersetzen, in welchem die Individualität der / [113] Ursprache allemal aufgegeben wird. Es geht also bei dem Gebrauche Einer solchen Schrift unter verschiednen Nationen immer hauptsächlich nur der Inhalt über, die Form wird wesentlich verändert, und der unläugbare Vorzug einer Begriffsschrift, Nationen verschiedner Sprachen verständlich zu seyn, wiegt die Nachtheile nicht auf, welche sie von andren Seiten her mit sich führt.

16- Als Lautschrift ist eine Begriffsschrift unvollkommen, weil sie Laute für Wörter angiebt, mithin der Sprache allen Gewinn entzieht, der, wie wir sehen werden, aus der Lautbezeichnung der Wortelemente entspringt. Sie wirkt aber auch niemals rein als Lautschrift. Da man der Geltung und dem Zusammenhang ihrer Zeichen nach Begriffen nachgehen kann, den Gedanken, gleichsam mit Uebergehung des Lautes, unmittelbar bilden, so wird sie dadurch zu einer eignen Sprache, und schwächt den natürlichen, vollen und reinen Eindruck der wahren und nationellen. Sie ringt auf der einen Seite, sich von der Sprache überhaupt, wenigstens von einer bestimmten frei zu machen, und schiebt auf der andren dem natürlichen Ausdruck der Sprache, dem Ton, die viel weniger angemessene Anschauung durch das Auge unter. Sie handelt daher dem instinctartigen Sprachsinn des Menschen gerade entgegen, und zerstört, je mehr sie sich mit Erfolg geltend macht, die Individualität der Sprachbezeichnung, die 
concept et néglige le son ne peut par conséquent exprimer cette individualité que de manière imparfaite. Un système fait de tels signes ne rend du monde extérieur ou intérieur que les concepts détachés; la langue doit contenir ce monde luimême, certes transformé en signes de pensées, mais dans toute la profusion de sa multiplicité riche, colorée et vivante.

15- Il n'y a cependant jamais vraiment eu d'écriture de concepts et il ne peut y en avoir qui soit uniquement composée de concepts, et sur laquelle les mots saisis en sons déterminés - mots de la langue pour laquelle cette écriture a été inventée n'auraient exercé l'influence la plus essentielle. Car puisque la langue est là avant l'écriture, cette dernière cherche évidemment un signe pour chaque mot et prend les signes au sens des mots de la langue qui leur correspondent, quand bien même ils auraient une valeur indépendante des sons, parce que subordonnés à un système conceptuel. Par conséquent toute écriture de concepts est toujours en même temps une écriture de sons et la question de savoir si et jusqu'à quel point elle peut en plus être considérée comme véritable écriture de concepts dépend du degré selon lequel l'utilisateur connaît et respecte la subordination systématique de ses signes, le code logique de leur formation. Qui connaît uniquement de manière mécanique les signes correspondant aux mots ne possède avec elle rien d'autre qu'une écriture de sons. Quand une telle écriture se transmet à une autre langue, on se trouve dans le même cas. Parce que dans la deuxième langue aussi, l'usage, si l'écriture doit réellement être écriture, doit attribuer à chaque signe la valeur d'un ou de plusieurs mots déterminés. Les signes d'écriture n'ont donc le même sens que dans la mesure où c'est aussi le cas pour les mots auxquels ils correspondent et la lecture d'un écrit dans l'une des deux langues devient toujours, pour qui ignore cette langue, une traduction, dans laquelle l'individualité de la $[\mathrm{V}, 113]$ langue originelle est à coup sûr abandonnée. Lors de l'utilisation d'une telle écriture par différentes nations, c'est toujours avant tout le contenu seul qui se transmet, la forme est substantiellement modifiée, si bien que l'avantage indéniable d'une écriture de concepts, qui est d'être compréhensible par des nations de langues différentes, ne compense pas les inconvénients qu'elle entraîne par ailleurs.

16- En tant qu'écriture de sons, une écriture de concepts est incomplète, parce qu'elle donne des sons pour les mots entiers et prive par conséquent la langue de tout le gain qui, comme nous allons le voir, provient de la désignation des éléments sonores du mot. Mais elle n'agit jamais purement comme une écriture de sons. Puisque l'on peut suivre la valeur et le rapport de ses signes à partir de concepts et former immédiatement des pensées, en passant pour ainsi dire pardessus les sons, elle devient une langue en elle-même et affaiblit l'impression naturelle, pleine et pure de la langue véritable et nationale. D'un côté, elle lutte pour se rendre libre du langage en général, du moins d'une langue déterminée, et de l'autre, elle substitue à l'expression naturelle de la langue, au son, la sensation visuelle qui lui est beaucoup moins appropriée. C'est pourquoi elle agit contre le sens du langage instinctif de l'homme et détruit, d'autant plus qu'elle se fait valoir avec succès, l'individualité de la désignation par le langage, 
allerdings nicht bloss in dem Laut einer jeden liegt, aber an denselben durch den Eindruck gebunden ist, den jede bestimmte Verknüpfung articulirter Töne unläugbar specifisch hervorbringt.

17- Das Bemühen, sich von einer bestimmten Sprache unabhängig zu machen, muss, da das Denken ohne Sprache einmal unmöglich ist, nachtheilig und verödend auf den Geist einwirken. Eine Begriffsschrift übt diese Nachtheile nur insofern nicht in dem hier geschilderten Grade aus, als ihr System nicht consequent durchgeführt ist, und als sie im Gebrauch phonetisch aufgenommen wird.

18- Die Buchstabenschrift ist von diesen Fehlern frei, einfaches, durch keinen Nebenbegriff zerstreuendes Zeichen des Zeichens, die Sprache überall begleitend, ohne sich ihr vorzudrängen, oder zur Seite zu stellen, nichts hervorrufend, als den Ton, und daher die natürliche Unterordnung bewahrend, in welcher der Gedanke nach dem durch den Ton gemachten Eindruck angeregt werden, und die Schrift ihn nicht an sich, sondern in dieser bestimmten Gestalt festhalten soll.

19- Durch dies enge Anschliessen an die eigenthümliche Natur / [114] der Sprache verstärkt sie gerade die Wirkung dieser, indem sie auf die prangenden Vorzüge des Bildes und Begriffsausdrucks Verzicht leistet. Sie stört die reine Gedankennatur der Sprache nicht, sondern vermehrt vielmehr dieselbe durch den nüchternen Gebrauch an sich bedeutungsloser Züge, und läutert und erhöht ihren sinnlichen Ausdruck, indem sie den im Sprechen verbundnen Laut in seine Grundtheile zerlegt, den Zusammenhang derselben unter einander, und in der Verknüpfung zum Wort anschaulich macht, und durch die Fixirung vor dem Auge auch auf die hörbare Rede zurückwirkt.

20- An diese Spaltung des verbundnen Lauts, als an das Wesen der Buchstabenschrift haben wir uns daher zu halten, wenn wir den inneren Einfluss derselben auf die Sprache beurtheilen wollen.

21- Die Rede bildet im Geiste des Sprechenden, bis sie einen Gedanken erschöpft, ein verbundnes Ganzes, in welchem erst die Reflexion die einzelnen Abschnitte aufsuchen muss. Dies erfährt man vorzüglich bei der Beschäftigung mit den Sprachen ungebildeter Nationen. Man muss theilen und theilen, und immer mistrauisch bleiben, ob das einfach Scheinende nicht auch noch zusammengesetzt ist. Gewissermassen ist freilich dasselbe auch bei den hochgebildeten der Fall, allein auf verschiedne Weise; bei diesen nur etymologisch zum Behuf der Einsicht in die Wortentstehung, bei jenen grammatisch und syntaktisch zum Behuf der Einsicht in die Verknüpfung der Rede. Das Verbinden des zu Trennenden ist allemal Eigenschaft des ungeübten Denkens und Sprechens; von dem Kinde und dem Wilden erhält man schwer Wörter, statt Redensarten. Die Sprachen von unvollkommnerem Bau überschreiten auch leicht das Mass dessen, was in einer grammatischen Form verbunden seyn darf. Die logische Theilung, welche die Gedankenverknüpfung auflöst, geht aber nur bis auf das einfache Wort. Die Spaltung dieses 
qui non seulement réside dans le son de toute langue, mais est en plus attachée à ce dernier par l'impression que chaque combinaison déterminée de sons articulés produit de manière indéniablement spécifique.

17- Puisque la pensée sans langue est simplement impossible, la tentative de se rendre indépendant d'une langue déterminée aura nécessairement un effet désavantageux et sclérosant sur l'esprit. Une écriture de concepts parvient à éviter des désavantages aussi graves qu'on les dépeint ici seulement dans la mesure où son système n'est pas appliqué de manière conséquente et où elle est saisie phonétiquement dans l'usage.

18- L'écriture alphabétique est exempte de ces défauts, elle est un simple signe de signe qui n'est perturbé par aucun concept accessoire, elle accompagne la langue partout sans s'imposer devant elle ni se mettre à côté d'elle, car elle ne fait naître rien d'autre que le son et conserve par conséquent la hiérarchie naturelle qui veut que la pensée soit éveillée grâce à l'impression produite par le son et que l'écriture ne puisse pas fixer la pensée en elle-même, mais dans la forme déterminée du son.

19- Par cette étroite connexion avec la nature particulière $[\mathrm{V}, 114]$ de la langue, l'écriture alphabétique renforce l'effet de cette dernière, en ce qu'elle renonce aux avantages éclatants de l'image et de l'expression directe du concept. Elle ne perturbe pas la nature de pure pensée de la langue, mais au contraire, elle l'intensifie par son usage sobre de traits qui en eux-mêmes n'ont aucune signification, et elle en affine et en élève l'expression sensible, parce qu'elle décompose en ses éléments fondamentaux le son qui est combiné dans la parole, qu'elle rend visibles le rapport de ces éléments entre eux et leur enchaînement dans le mot et que, en les fixant pour l'œil, elle agit en retour sur le discours audible".

20- Nous devons par conséquent avoir en tête cette segmentation du son combiné, en tant qu'essence de l'écriture alphabétique, si nous voulons juger de l'influence intime de celle-ci sur la langue.

21- Jusqu'à ce qu'il ait épuisé une pensée, le discours forme, dans l'esprit du locuteur, une totalité liée, dont les parties individuelles doivent d'abord être cherchées par la réflexion. On fait l'expérience de cela en particulier lorsqu'on s'occupe des langues des nations peu cultivées. On doit diviser et diviser, et toujours demeurer méfiant, vérifier si le constituant qui paraît simple ne serait pas encore un composé. Jusqu'à un certain point, c'est aussi le cas, bien sûr, avec les nations cultivées, mais d'une manière différente : chez celles-ci, c'est seulement au plan étymologique, pour comprendre la genèse des mots; chez celles-là, c'est au plan grammatical et syntaxique, pour comprendre la liaison du discours. Relier ce qui doit être séparé, c'est à coup sûr la propriété d'une pensée et d'une parole non exercées; des enfants et des sauvages, on obtient difficilement des mots plutôt que des tournures. Les langues dont la structure est moins parfaite dépassent elles aussi aisément la limite de ce qu'une forme grammaticale permet de lier. La division logique, qui dénoue l'enchaînement des pensées, va néanmoins seulement jusqu'au mot simple. La segmentation du 
ist das Geschäft der Buchstabenschrift. Eine Sprache, die sich einer andren Schrift bedient, vollendet daher das Theilungsgeschäft der Sprache nicht, sondern macht einen Stillstand, wo die Vervollkommnung der Sprache weiter zu gehen gebietet.

22- Zwar ist die Aufsuchung der Lautelemente auch ohne den Gebrauch der Buchstabenschrift denkbar, und die Chinesen besitzen namentlich eine Analyse der verbundnen Laute, indem sie die Zahl und Verschiedenheit ihrer Anfangsund End-Articulationen und ihrer Wortbetonungen bestimmt und genau angeben. Da / [115] aber nichts weder in der gewöhnlichen Sprache, noch in der Schrift (insofern sie nemlich wirklich Zeichenschrift ist, da die Chinesen bekanntlich dieser auch Lautbezeichnung beimischen) zu dieser Analyse nöthigt, so kann sie schon darum nicht so allgemein seyn. Da ferner der einzelne Ton (Consonant und Vocal) nicht durch ein nur ihm angehörendes Zeichen isolirt dargestellt, sondern nur den Anfängen und Endigungen verbundner Laute abgehört wird, so ist die Darstellung des Tonelements nie so rein und anschaulich, als durch die Buchstabenschrift, und die Lautanalyse, wenn ihr auch nichts an Vollständigkeit und Genauigkeit abgienge, macht nicht auf den Geist den Eindruck einer rein vollendeten Sprachtheilung. Bei der inneren Wirkung der Sprachen aber, welche allein ihre wahren Vorzüge bestimmt, kommt Alles auf das volle und reine Wirken jedes Eindrucks an, und der geringste, im äusseren Erfolg gar nicht bemerkbare Mangel an einem von beiden ist von Erheblichkeit. Das alphabetische Lesen und Schreiben dagegen nöthigt in jedem Augenblick zum Anerkennen der zugleich dem Ohr und dem Auge fühlbaren Lautelemente, und gewöhnt an die leichte Trennung und Zusammensetzung derselben; es macht daher eine vollendet richtige Ansicht der Theilbarkeit der Sprache in ihre Elemente in eben dem Grade allgemein, in welchem es selbst über die Nation verbreitet ist.

23- Zunächst äussert sich diese berichtigte Ansicht in der Aussprache, die, durch das Erkennen und Ueben der Lautelemente in abgesonderter Gestalt, befestigt und geläutert wird. So wie für jeden Laut ein Zeichen gegeben ist, gewöhnen sich das Ohr und die Sprachorgane, ihn immer genau auf dieselbe Weise zu fordern und wiederzugeben; zugleich wird er, mit Abschneidung des unbestimmten Tönens, mit dem, im ungebildeten Sprechen, ein Laut in den andren überfliesst, schärfer und richtiger begränzt. Diese reinere Aussprache, die feine Ausbildung des Ohrs und der Sprachwerkzeuge ist schon an sich, und in ihrer Wirkung auch auf das Innre der Sprache von der äussersten Wichtigkeit; die Absonderung der Lautelemente übt aber auch einen noch tiefer in das Wesen der Sprache eingehenden Einfluss aus.

24- Sie führt nemlich der Seele die Articulation der Töne vor, indem sie die articulirten Töne vereinzelt und bezeichnet. Die alphabetische Schrift thut dies klarer und anschaulicher, als es auf irgend einem andren Wege geschehen könnte, und man behauptet nicht zu viel, wenn man sagt, dass durch das Alphabet einem / [116] Volke eine ganz neue Einsicht in die Natur der Sprache 
mot est l'opération de l'écriture alphabétique. Par conséquent, une langue qui se sert d'une autre écriture ne parachève pas la tâche de division du langage, mais provoque une interruption là où le perfectionnement de la langue commande que l'on aille plus loin.

22- La recherche des éléments sonores est certes pensable sans l'usage de l'alphabet et les Chinois en particulier possèdent une analyse des sons combinés, du fait qu'ils indiquent de manière déterminée et précise le nombre et la diversité de leurs articulations initiales et finales ainsi que de leurs accents de mot. Mais [V, 115] puisque rien, ni dans la langue habituelle, ni dans l'écriture (dans la mesure où celle-ci est vraiment en effet une écriture en signes, puisque les Chinois, comme on sait, y incorporent aussi la désignation des sons), ne contraint à cette analyse, celle-ci peut, pour cette raison, n'être pas aussi générale. Puisque, en plus, le son individuel (consonne et voyelle) n'est pas représenté isolément à l'aide d'un signe qui lui appartient en propre, mais seulement capté par les initiales et finales des sons combinés, la représentation de l'élément sonore n'est pas aussi pure et sensible qu'elle ne l'est dans l'écriture alphabétique et l'analyse des sons, quand bien même rien en elle ne manquerait de complétude et d'exactitude, ne produit pas sur l'esprit l'impression d'une division entièrement accomplie de la langue. Dans l'effet intérieur des langues cependant, qui seul détermine leurs véritables avantages, tout se fonde sur l'effet entier et pur de chaque impression et le plus petit défaut de complétude et d'exactitude, imperceptible dans le résultat extérieur, porte à conséquence. Lire et écrire selon l'alphabet par contre oblige à chaque instant à la reconnaissance des éléments sonores perceptibles à la fois à l'oreille et à l'œil, et habitue à séparer et à réunir facilement ces éléments ; cela procure par conséquent une vision réellement achevée de la divisibilité de la langue en ses éléments, et ce de manière aussi générale que l'écriture alphabétique est elle-même répandue dans la nation.

23- Cette vision corrigée se manifeste en premier lieu dans la prononciation, qui, par la reconnaissance et la répétition des éléments sonores en leur forme isolée, se raffermit et s'affine. Ainsi, comme il y a un signe pour chaque son ${ }^{10}$, l'oreille et les organes de la parole s'habituent à susciter et à reproduire celui-ci toujours plus exactement de la même manière ; en même temps, en éliminant des sonorités indéterminées là où, dans le parler peu cultivé, un son déborde sur l'autre, on délimite le son de manière plus précise et plus juste. Cette prononciation plus nette, la fine formation de l'oreille et des organes de la parole, est déjà en ellemême, ainsi que dans son effet sur l'intérieur de la langue, de la plus grande importance; l'isolement des éléments sonores exerce cependant aussi une influence qui pénètre plus profondément dans l'essence de la langue.

24- C'est que l'écriture alphabétique présente à l'âme l'articulation des sons, en individualisant et en désignant les sons articulés. Elle fait cela de façon plus claire et sensible que cela ne pourrait être fait par quelque autre voie et l'on ne s'avance pas trop en disant que, par l'alphabet, [V, 116] une toute nouvelle perspective sur la nature de la langue se révèle au peuple ${ }^{11}$. Puisque 
aufgeht. Da die Articulation das Wesen der Sprache ausmacht, die ohne dieselbe nicht einmal möglich seyn würde, und der Begriff der Gliederung sich über ihr ganzes Gebiet, auch wo nicht bloss von Tönen die Rede ist, erstreckt; so muss die Versinnlichung und Vergegenwärtigung des gegliederten Tons vorzugsweise mit der ursprünglichen Richtigkeit und der allmählichen Entwicklung des Sprachsinnes in Zusammenhang stehen. Wo dieser stark und lebendig ist, wird ein Volk aus eignem Drange der Erfindung des Alphabets entgegengehen, und wo ein Alphabet einer Nation von der Fremde her zukommt, wird es die Sprachausbildung in ihr befördern und beschleunigen.

25- Obgleich der articulirte Laut körperlich und instinctartig hervorgebracht ist, so stammt sein Wesen doch eigentlich nur aus der inneren Seelenanlage zur Sprache, die Sprachwerkzeuge besitzen bloss die Fähigkeit, sich dem Drange dieser gemäss zu gestalten. Eine Definition des articulirten Lauts, bloss nach seiner physischen Beschaffenheit, ohne die Absicht oder den Erfolg seiner Hervorbringung darin aufzunehmen, scheint mir daher unmöglich. Er ist ein sich einzeln abschneidender Laut, nicht ein verbundnes und vermischtes Tönen oder Schmettern, wie die meisten Gefühllaute. Sein charakteristischer Unterschied liegt nicht, musikalisch, in der Höhe und Tiefe, da er durch die ganze Tonleiter hindurch angestimmt werden kann. Derselbe beruht ebensowenig auf der Dehnung und Verkürzung, Helligkeit oder Dumpfheit, Härte oder Weiche, da diese Verschiedenheiten theils Eigenschaften aller articulirten Töne seyn können, theils Gattungen derselben bilden. Versucht man nun aber die Unterschiede zwischen $a$ und $e, p$ und $k$ u. s. w. auf einen allgemeinen sinnlichen Begriff zurückzuführen, so ist mir wenigstens bis jetzt dies immer mislungen. Es bleibt nichts übrig, als überhaupt zu sagen, dass diese Töne, unabhängig von jenen Kennzeichen, dennoch specifisch verschieden sind, oder dass ihr Unterschied aus einem bestimmten Zusammenwirken der Organe entsteht, oder eine andre ähnliche Beschreibung zu versuchen, die aber nie eine wahre Definition giebt. Erschöpfend und ausschliessend wird ihr Wesen immer nur dadurch geschildert, dass man ihnen die Eigenschaft zuschreibt, unmittelbar durch ihr Ertönen Begriffe hervorzubringen, indem theils jeder einzelne dazu gebildet ist, theils die Bildung des einzelnen eine in bestimmbaren Classen bestimmbare Anzahl / [117] gleichartiger, aber specifisch verschiedner möglich macht und fordert, welche nothwendige oder willkührliche Verbindungen mit einander einzugehen geeignet sind. Hierdurch ist jedoch nicht mehr gesagt, als dass articulirte Laute Sprachlaute und umgekehrt sind.

26- Die Sprache aber liegt in der Seele, und kann sogar bei widerstrebenden Organen und fehlendem äusseren Sinn hervorgebracht werden. Dies sieht man bei dem Unterrichte der Taubstummen, der nur dadurch möglich wird, dass der innere Drang der Seele, die Gedanken in Worte zu kleiden, demselben entgegenkommt, und vermittelst erleichternder Anleitung den Mangel ersetzt, und die Hindernisse besiegt. Aus der individuellen Beschaffenheit dieses 
l'articulation (Articulation) constitue l'essence du langage, qui sans elle ne serait même pas possible, et que le concept d'articulation (Gliederung) ${ }^{12}$ s'étend à son domaine entier (même là où il n'est plus question seulement des sons), le procédé qui rend le son articulé sensible et mentalement présent doit de préférence être en rapport avec la justesse originelle et l'évolution graduelle du sens du langage. Là où ce sens est fort et vivant, un peuple sera amené par sa propre impulsion à inventer l'alphabet, et là où un alphabet vient de l'étranger à une nation, il favorisera et accélérera chez celle-ci le développement de la langue.

25- Bien que le son articulé soit émis de manière corporelle et instinctive, son essence provient seulement, en fait, de la disposition intérieure de l'âme au langage, les organes de la parole possèdent seulement la capacité de se former suivant l'impulsion de cette disposition. Une définition du son articulé qui ne se fonderait que sur sa qualité physique et ne prendrait pas en compte l'intention et le résultat de sa production me semble par conséquent impossible ${ }^{13}$. C'est un son qui se découpe de manière individuelle et non pas, comme le sont la plupart des sons exprimant des sentiments ou des sensations, une résonance ou une répercussion liée et mêlée. Sa différence caractéristique ne réside pas, musicalement, dans l'aigu ou le grave, parce qu'il peut être émis dans la gamme entière. Elle ne repose pas plus sur sa longueur ou sa brièveté, son éclat ou sa matité, sa dureté ou sa douceur, en partie parce que ces distinctions peuvent être des propriétés de tous les sons articulés, en partie parce qu'elles forment les genres de ceux-ci. Or on peut bien essayer de ramener à un concept sensible général les différences entre $a$ et $e, p$ et $k$, etc. ; mais pour ma part j'ai toujours échoué dans une telle tentative, du moins jusqu'à maintenant. Le seul choix qui nous reste au fond est de dire que ces sons, indépendamment des caractéristiques qu'on vient de mentionner, sont malgré tout spécifiquement distincts, ou bien que leur différence naît d'une certaine action d'ensemble des organes, ou bien de tenter une autre description semblable, qui ne donne cependant jamais une véritable définition. Leur essence ne sera dépeinte de manière exhaustive et exclusive que si on leur attribue la propriété de produire immédiatement des concepts en résonant, en partie en ce que chaque son individuel est formé pour cela, en partie en ce que la formation de chacun rend possible et requiert, dans des classes définissables, un nombre définissable [V, 117] des sons similaires mais spécifiquement distincts, qui sont aptes à conclure des liaisons nécessaires ou arbitraires les uns avec les autres. Mais par là même on n'a rien dit de plus que ceci : les sons articulés sont des sons du langage et inversement.

26- Le langage réside cependant dans l'âme et peut être produit même lorsque les organes n'obéissent pas ou lorsqu'il manque un sens externe. On le voit dans l'enseignement aux sourds-muets, qui est possible seulement parce que l'impulsion intérieure de l'âme à habiller de mots les pensées le soutient, et que, à l'aide d'instruction facilitantes, cette impulsion pallie le manque et vainc les obstacles ${ }^{14}$. Le système de sons propre à chaque langue naît de la nature 
Dranges, verständliche Laute hervorzubringen, aus der Individualität des Lautgefühls (überhaupt in Hinsicht des Lautes, als solchen, des musikalischen Tons und der Articulation), und endlich aus der Individualität des Gehörs und der Sprachwerkzeuge entsteht das besondre Lautsystem jeder Sprache, und wird, sowohl durch seine ursprüngliche Gleichartigkeit mit der ganzen Sprachanlage des Individuums, als in seinen tausendfachen, einzeln gar nicht zu verfolgenden Einflüssen auf alle Theile des Sprachbaues, die Grundlage der besondren Eigenthümlichkeit der ganzen Sprache selbst. Die aus der Seele heraustönende specifische Sprachanlage verstärkt sich in ihrer Eigenthümlichkeit, indem sie wieder ihr eignes Tönen, als etwas fremdes Erklingendes, vernimmt.

27- Wenn gleich jede wahrhaft menschliche Thätigkeit der Sprache bedarf, und diese sogar die Grundlage aller ausmacht, so kann doch eine Nation die Sprache mehr oder weniger eng in das System ihrer Gedanken und Empfindungen verweben. Es beruht dies auch nicht bloss, wie man wohl zuweilen zu glauben pflegt, auf ihrer Geistigkeit überhaupt, ihrer mehr oder weniger sinnigen Richtung, ihrer Neigung zu Wissenschaft und Kunst, noch weniger auf ihrer Cultur, einem höchst vieldeutigen, und mit der grössesten Behutsamkeit zu brauchenden Worte. Eine Nation kann in allen diesen Rücksichten vorzüglich seyn, und dennoch der Sprache kaum das ihr gebührende Recht einräumen.

28- Der Grund davon liegt in Folgendem. Wenn man sich das Gebiet der Wissenschaft und Kunst auch völlig abgesondert von Allem denkt, was sich auf die Anordnung des physischen Lebens / [118] bezieht, so giebt es für den Geist doch mehrere Wege dahin zu gelangen, von denen nicht jeder die Sprache gleich stark und lebendig in Anspruch nimmt. Diese lassen sich theils nach Gegenständen der Erkenntniss bestimmen, wobei ich nur an die bildende Kunst und die Mathematik zu erinnern brauche, theils nach der Art des geistigen Triebes, der mehr die sinnliche Anschauung suchen, trocknem Nachdenken nachhängen, oder sonst eine, nicht der ganzen Fülle und Feinheit der Sprache bedürfende Richtung nehmen kann.

29- Zugleich liegt, wie schon oben bemerkt ist, auch in der Sprache ein Doppeltes, durch welches das Gemüth nicht immer in der nothwendigen Vereinigung berührt wird; sie bildet Begriffe, führt die Herrschaft des Gedanken in das Leben ein, und thut es durch den Ton. Die geistige Anregung, die sie bewirkt, kann dahin führen, dass man, vorzugsweise von dem Gedanken getroffen, ihn zugleich auf einem andren, unmittelbareren Wege, entweder sinnlicher, oder reiner, unabhängiger von einem, als zufällig erscheinenden Schall, aufzufassen versucht; alsdann wird das Wort nur als Nebenhülfe behandelt. Es kann aber auch gerade der in Töne gekleidete Gedanke die Hauptwirkung auf das Gemüth ausüben, gerade der Ton, zum Worte geformt, begeistern, und alsdann ist die Sprache die Hauptsache, und der Gedanke erscheint nur als hervorspriessend aus ihr, und untrennbar in sie verschlungen.

30- Wenn man daher die Sprachen mit der Individualität der Nationen vergleicht, so muss man zwar zuerst die geistige Richtung derselben überhaupt, nachher aber immer vorzüglich den eben erwähnten Unterschied beachten, die 
individuelle de cette impulsion à produire des sons compréhensibles, de l'individualité de la sensation du son (au point de vue du son comme tel, du son musical et de l'articulation) et enfin, de l'individualité de l'ouïe et des organes de la parole, et ce système devient - autant par son homogénéité originaire avec toute la disposition linguistique de l'individu que dans ses influences multiples, impossibles à suivre isolément, sur toutes les parties de la structure de la langue le fondement des propriétés particulières de la langue elle-même dans son ensemble. La disposition linguistique spécifique, qui sonne depuis l'âme, se renforce dans sa particularité en ce qu'elle entend de nouveau sa propre sonorité comme un retentir quelque peu étranger.

27- Quoique chaque activité véritablement humaine exige le langage et que celuici constitue même le fondement de toutes, une nation peut malgré tout tisser la langue de manière plus ou moins étroite dans le système de ses pensées et sensations. Cela ne repose pas seulement, comme on aime parfois à le croire, sur sa spiritualité ${ }^{15}$ même, sur le caractère plus ou moins réfléchi de son orientation, sur son inclination à la science et à l'art, encore moins sur son degré de civilisation, un mot hautement équivoque et qui doit être employé avec la plus grande précaution. Une nation peut être à tous ces égards excellente et cependant ne pas rendre dûment justice à sa langue.

28- La raison de cela est la suivante : si on pense au domaine de la science et de l'art indépendamment de ce qui se rapporte à l'ordre de l'existence physique, [V, 118] on constate que plusieurs voies s'offrent à l'esprit pour réussir dans ces domaines-là, qui toutes ne recourent pas au langage de manière également forte et vivante. Ces voies peuvent être déterminées en partie par l'objet de la connaissance - ici je n'ai qu'à évoquer les beaux-arts et les mathématiques -, en partie d'après la forme d'élan spirituel, qui peut davantage rechercher l'intuition sensible, se livrer à la froide réflexion ou prendre une autre direction qui ne nécessite pas toute la plénitude et la finesse du langage.

29- En même temps, comme on l'a déjà observé plus haut, il existe aussi dans la langue une dualité qui fait que l'âme n'est pas toujours touchée dans l'union nécessaire ; la langue forme des concepts, introduit la maitrise de la pensée dans la vie et fait cela par le son. La stimulation qu'elle exerce sur l'esprit peut avoir pour conséquence que l'on tente, frappé de préférence par la pensée, de saisir celle-ci par une autre voie, plus immédiate, ou plus sensible, ou plus pure, plus indépendante d'un bruit qui apparaît fortuit; le mot n'est dans ce cas traité que comme une ressource auxiliaire. Cependant, ça peut être aussi précisément la pensée habillée de sons qui exerce l'action principale sur l'âme, ça peut être précisément le son formé en mot qui enthousiasme, et dès lors la langue est la chose principale et la pensée n'apparaît que comme émanant d'elle, et entrelacée à elle, inséparablement.

30- Si, par conséquent, on compare les langues avec l'individualité des nations, on doit certes prêter attention à l'orientation spirituelle générale de celles-ci, mais ensuite on doit toujours en premier lieu observer la différence qui vient 
Neigung zum Ton, das feine Unterscheidungsgefühl seiner unendlichen Anklänge an den Gedanken, die leise Regsamkeit, durch ihn gestimmt zu werden, dem Gedanken tausendfache Formen zu geben, auf welche, gerade weil sie in der Fülle seines sinnlichen Stoffes ihre Anregung finden, der Geist von oben herab, durch Gedankeneintheilung nie zu kommen vermöchte. Es liesse sich leicht zeigen, dass diese Richtung für alle geistige Thätigkeiten die am gelingendsten zum Ziel führende seyn muss, da der Mensch nur durch Sprache Mensch, und die Sprache nur dadurch Sprache ist, dass sie den Anklang zu dem Gedanken allein in dem Wort sucht. Wir können aber dies für jetzt übergehen, und nur dabei stehen bleiben, dass die Sprache wenigstens auf keinem Wege eine / [119] grössere Vollkommenheit erlangen kann, als auf diesem. Was nun die Articulation der Laute, oder, wie man sie auch nennen kann, ihre gedankenbildende Eigenschaft hervorhebt, und ins Licht stellt, wird in dieser geistigen Stimmung begierig gesucht oder ergriffen werden, und so muss die Buchstabenschrift, welche die Articulation der Laute, zuerst bei dem Aufzeichnen, hernach bei allgemein werdender Gewohnheit, bei dem innersten Hervorbringen der Gedanken, der Seele unablässig vorführt, in dem engsten Zusammenhange mit der individuellen Sprachanlage jeder Nation stehen. Auch erfunden oder gegeben, wird sie ihre volle und eigenthümliche Wirkung nur da ausüben, wo ihr die dunkle Empfindung des Bedürfnisses nach ihr schon vorangieng.

31- So unmittelbar an die innerste Natur der Sprache geknüpft, übt sie nothwendig ihren Einfluss auf alle Theile derselben aus, und wird von allen Seiten her in ihr gefordert. Ich will jedoch nur an zwei Punkte erinnern, mit welchen ihr Zusammenhang vorzüglich einleuchtend ist, an die rhythmischen Vorzüge der Sprachen, und die Bildung der grammatischen Formen.

32- Ueber den Rhythmus ist es in dieser Beziehung kaum nöthig, etwas hinzuzufügen. Das reine und volle Hervorbringen der Laute, die Sonderung der einzelnen, die sorgfältige Beachtung ihrer eigenthümlichen Verschiedenheit kann da nicht entbehrt werden, wo ihr gegenseitiges Verhältniss die Regel ihrer Zusammenreihung bildet. Es hat gewiss rhythmische Dichtung bei allen Nationen vor dem Gebrauch einer Schrift gegeben, auch regelmässig sylbenmessende bei einigen, und bei wenigen, vorzüglich glücklich organisirten hohe Vortreflichkeit in dieser Behandlung. Es muss diese aber unläugbar durch das Hinzukommen des Alphabetes gewinnen, und vor dieser Epoche zeugt sie selbst schon von einem solchen Gefühl der Natur der einzelnen Sprachlaute, dass eigentlich nur das Zeichen dafür noch mangelt, wie auch in andren Bestrebungen der Mensch oft erst von der Hand des Zufalls den sinnlichen Ausdruck für dasjenige erwarten muss, was er geistig längst in sich trägt. Denn bei der Würdigung des Einflusses der Buchstabenschrift auf die Sprache ist vorzüglich das zu beachten, dass auch in ihr eigentlich zweierlei liegt, die Sonderung der articulirten Laute, und ihre äussren Zeichen. Wir haben schon oben, bei Gelegenheit der Chinesen, bemerkt, und die Behauptung lässt sich, unter Umständen, auch auf wahrhaft alphabetische Schrift ausdehnen, dass nicht 
d'être évoquée, l'inclination pour le son, l'aptitude à discerner avec subtilité ses échos infinis aux pensées, la douce agilité, qui nous est accordée par lui, pour donner à la pensée des formes multiples auxquelles l'esprit, précisément parce que ces formes sont éveillées par la plénitude de sa matière sensible, ne pourrait jamais parvenir de haut en bas, par la division de la pensée. Il serait facile de démontrer que cette orientation est celle qui, pour toutes les activités de l'esprit, conduit avec le plus de succès au but, parce que l'humain n'est humain que par le langage et que le langage n'est langage que parce qu'il cherche seulement dans le mot l'écho de la pensée. Mais nous pouvons laisser cela de côté pour le moment et nous en tenir seulement au fait que la langue, à tout le moins, ne peut atteindre à une $[\mathrm{V}, 119]$ perfection plus grande par une autre voie que celle-ci. Ce que fait ressortir et met en lumière l'articulation des sons, ou bien, comme on peut la nommer aussi, sa qualité de former des pensées, sera cherché ou saisi avec avidité dans cette tonalité spirituelle, si bien que l'écriture alphabétique, qui présente continuellement à l'âme l'articulation des sons - d'abord par l'action de tracer, ensuite par l'habitude devenue générale, par la production la plus intime des pensées - doit être dans le rapport le plus étroit avec les dispositions linguistiques individuelles de chaque nation. Qu'elle soit découverte ou donnée, l'écriture alphabétique n'exercera pleinement son effet particulier que là où la sensation confuse de son besoin l'avait déjà précédée.

31- Ainsi nouée directement à la nature la plus intérieure de la langue, elle exerce nécessairement son influence sur toutes les parties de cette dernière, qui exige une telle écriture de toutes parts. Je ne veux cependant aborder que deux points, dont le rapport avec l'écriture alphabétique est particulièrement éclairant, soit les caractères rythmiques des langues et l'élaboration des formes grammaticales.

32- Sur le rythme, il est à peine nécessaire, sous ce rapport, d'ajouter quelque chose. La production pure et entière des sons, la séparation des sons individuels, l'observation attentive de leur différence particulière ne peuvent être escamotées là où leurs relations réciproques forment la règle de leur enchaînement. Il y a certes eu, avant l'utilisation de l'écriture, de la poésie rythmée dans toutes les nations, ainsi que, dans quelques-unes, de la poésie aux syllabes mesurées régulièrement, et, dans un petit nombre d'entre elles, particulièrement bien organisées, un haut degré d'excellence dans cette pratique. Mais il est incontestable que la poésie a bénéficié de l'arrivée de l'alphabet et avant cette époque elle témoignait déjà d'un tel sentiment de la nature des sons individuels du langage que seul le signe pour cela faisait défaut, tout comme, dans d'autres tentatives, l'homme doit souvent attendre l'intervention du hasard avant de trouver l'expression sensible apte à manifester ce qu'il porte dans son esprit depuis longtemps. Car, pour reconnaître l'influence de l'écriture alphabétique sur la langue, il faut accorder une attention privilégiée au fait que résident en elle deux choses, la séparation des sons articulés et leurs signes extérieurs. Nous avons déjà observé plus haut, en traitant de l'écriture chinoise - et l'affirmation peut s'étendre également, dans certaines circonstances, à une vraie écriture 
jeder / [120] Gebrauch einer Lautbezeichnung den entscheidenden Einfluss auf die Sprache hervorbringt, den die Auffassung der Buchstabenschrift in ihrem wahren Geist einer Nation und ihrer Sprache allemal zusichert. Wo dagegen, auch noch ohne den Besitz alphabetischer Zeichen, durch die hervorstechende Sprachanlage eines Volks jene innere Wahrnehmung des articulirten Lauts (gleichsam der geistige Theil des Alphabets) vorbereitet und entstanden ist, da geniesst dasselbe, schon vor der Entstehung der Buchstabenschrift, eines Theils ihrer Vorzüge.

33- Daher sind Sylbenmasse, die sich, wie der Hexameter und der sechzehnsylbige Vers der Slocas aus dem dunkelsten Alterthum her auf uns erhalten haben, und deren blosser Sylbenfall noch jetzt das Ohr in einen unnachahmlichen Zauber wiegt, vielleicht noch stärkere und sichrere Beweise des tiefen und feinen Sprachsinns jener Nationen, als die Ueberbleibsel ihrer Gedichte selbst. Denn so eng auch die Dichtung mit der Sprache verschwistert ist, so wirken doch natürlich mehrere Geistesanlagen zusammen auf sie; die Auffindung einer harmonischen Verflechtung von Sylben-Längen und Kürzen aber zeugt von der Empfindung der Sprache in ihrer wahren Eigenthümlichkeit, von der Regsamkeit des Ohrs und des Gemüths, durch das Verhältniss der Articulationen dergestalt getroffen und bewegt zu werden, dass man die einzelnen in den verbundnen unterscheidet, und ihre Tongeltung bestimmt und richtig erkennt.

34- Dies liegt allerdings zum Theil auch in dem, der Sprache nicht unmittelbar angehörenden musikalischen Gefühl. Denn der Ton besitzt die glückliche Eigenthümlichkeit, das Idealische auf zwei Wegen, durch die Musik und die Sprache, berühren, und diese beiden mit einander verbinden zu können, woher der von Worten begleitete Gesang wohl unbestreitbar im ganzen Gebiete der Kunst, weil sich zwei ihrer bedeutendsten Formen in ihm vereinen, die vollste und erhebendste Empfindung hervorbringt. Je lebendiger aber jene Sylbenmasse auch für die musikalische Anlage ihrer Erfinder sprechen, desto mehr zeugen sie von der Stärke ihres Sprachsinnes, da gerade durch sie dem articulirten Laut, also der Sprache, neben der hinreissenden Gewalt der Musik, sein volles Recht erhalten wird. Denn die antiken Sylbenmasse unterscheiden sich eben dadurch am allgemeinsten von den modernen, dass sie, auch in dem musikalischen Ausdruck, den Laut immer wahrhaft als Sprachlaut behandeln, die wieder- / [121] kehrende, vollständige oder unvollständige Gleichheit verbundner Laute (Reim und Assonanz), die auf den blossen Klang hinausläuft, verschmähen, und nur sehr selten die Sylben gegen ihre Natur, bloss der Gewalt des Rhythmus gehorchend, zu dehnen oder zu verkürzen erlauben, sondern genau dafür sorgen, dass sie in ihrer natürlichen Geltung, klar und unverändert austönend, harmonisch zusammenklingen.

35- Die Beugung, auf welcher das Wesen der grammatischen Formen beruht, führt nothwendig auf die Unterscheidung und Beachtung der einzelnen Articulationen. Wenn eine Sprache nur bedeutsame Laute an einander knüpft, oder es 
alphabétique -, que ce n'est pas toute $[\mathrm{V}, 120]$ utilisation d'une désignation des sons qui produit une influence décisive sur la langue, influence que la compréhension de l'écriture alphabétique dans son esprit véritable garantit toujours à une nation et à une langue. Là où, par contre, même sans la possession de signes alphabétiques, grâce aux dispositions linguistiques remarquables d'un peuple, cette perception interne du son articulé (la part spirituelle de l'alphabet, en quelque sorte) a été préparée puis est apparue, le peuple jouit d'une partie des avantages de l'écriture alphabétique, même avant l'apparition de celle-ci.

33- C'est pourquoi les mètres qui, tels l'hexamètre et le vers de seize syllabes des shloca ${ }^{16}$, se sont conservés depuis la plus obscure Antiquité jusqu'à nous et dont la cadence syllabique simple berce l'oreille encore aujourd'hui d'un charme inimitable sont peut-être des preuves encore plus fortes et plus sûres du sens profond et raffiné du langage de ces nations que les vestiges de leurs poèmes eux-mêmes. Car aussi étroitement que soit unie la poésie à la langue, elle subira quand même évidemment l'action simultanée de plusieurs dispositions spirituelles ; la découverte d'un entrelacement harmonieux de syllabes longues et brèves témoigne cependant d'un sentiment de la langue dans sa véritable particularité, de l'agilité de l'oreille et de l'âme à être touchées et émues par la relation des articulations, de telle sorte qu'on distingue les syllabes individuelles dans celles qui sont liées et qu'on reconnaît leur valeur tonale de manière sûre et juste.

34- Cela tient aussi bien sûr en partie au sentiment musical qui n'appartient pas immédiatement à la langue. Car le son possède l'heureuse particularité de toucher à l'idéal de deux manières, par la musique et par la langue, et de pouvoir lier celles-ci l'une à l'autre, d'où vient que le chant accompagné de mots produit incontestablement, dans tout le domaine de l'art, le sentiment le plus complet et le plus exaltant, parce que deux de ses formes les plus significatives s'y réunissent ${ }^{17}$. Plus ces mètres-là montrent la vivacité des dispositions musicales de leurs inventeurs, plus ils témoignent de la force de leur sens du langage, parce que c'est précisément à travers eux que le son articulé, donc la langue, obtiendra son plein droit à côté de la puissance entraînante de la musique. Car les mètres antiques se distinguent justement des modernes le plus généralement par le fait que, même dans l'expression musicale, ils traitent toujours le son réellement comme un son du langage, ils dédaignent $[\mathrm{V}, 121]$ les retours de combinaisons sonores partiellement ou entièrement semblables (rimes et assonances) qui aboutissent au seul timbre, et ils ne s'autorisent que très rarement à allonger ou à raccourcir contre leur nature les syllabes en obéissant seulement à la puissance du rythme, mais se soucient plutôt que les syllabes forment des accords harmonieux, en résonant de façon claire et inaltérée, dans leur valeur naturelle.

35- La flexion, sur laquelle se fonde l'essence des formes grammaticales, conduit nécessairement à la différenciation et à l'observation des articulations individuelles. Quand une langue n'agglutine l'un à l'autre que des sons avec 
wenigstens nicht versteht, die grammatischen Bezeichnungen mit den Wörtern fest zusammenzuschmelzen, so hat sie es nur mit Lautganzen zu thun, und wird nicht $\mathrm{zu}$ der Unterscheidung einer einzelnen Articulation, wie durch das Erscheinen des nemlichen, nur in seinen Beugungen verschiednen Wortes angeregt. So wie daher Feinheit und Lebendigkeit des Sprachsinnes zu festen grammatischen Formen führen, so befördern diese die Anerkennung des Alphabetes, als Lauts, welcher hernach leichter die Erfindung, oder fruchtbarere Benutzung der sichtbaren Zeichen folgt. Denn wo sich ein Alphabet zu einer grammatisch noch unvollkommneren Sprache gesellt, kann Beugung durch Hinzufügung und Umänderung einzelner Buchstaben gebildet, die vorhandne sichrer bewahrt, und die noch halb in Anfügung begriffene reiner abgeschieden werden.

36- Wodurch aber die Buchstabenschrift noch viel wesentlicher, obgleich nicht so sichtlich an einzelnen Beschaffenheiten erkennbar, auf die Sprache wirkt, ist dadurch, dass sie allein erst die Einsicht in die Gliederung derselben vollendet, und das Gefühl davon allgemeiner verbreitet. Denn ohne die Unterscheidung, Bestimmung und Bezeichnung der einzelnen Articulationen, werden nicht die Grundtheile des Sprechens erkannt, und der Begriff der Gliederung wird nicht durch die ganze Sprache durchgeführt. Jeden in einem Gegenstande liegenden Begriff aber vollständig durchzuführen, ist überhaupt und überall von der grössesten Wichtigkeit, und noch mehr da, wo der Gegenstand, wie die Sprache, ganz ideal ist, und wo, theils zugleich, theils nach einander, der Instinct handelt, das Gefühl ahndet, der Verstand einsieht, und die Verstandeseinsicht wieder auf das Gefühl, und dieses auf den Instinct berichtigend zurückwirkt. Die Folgen des Mangels / [122] davon erstrecken sich weit über den unvollendet bleibenden Theil hinaus, bei den Sprachen ohne Buchstabenschrift, und ohne sichtbare Spuren eines nach derselben empfundnen Bedürfnisses, nicht bloss auf die richtige und vollständige Einsicht in die Articulation der Laute, sondern über die ganze Art ihres Baues und ihres Gebrauchs. Die Gliederung ist aber gerade das Wesen der Sprache; es ist nichts in ihr, das nicht Theil und Ganzes seyn könnte, die Wirkung ihres beständigen Geschäfts beruht auf der Leichtigkeit, Genauigkeit und Uebereinstimmung ihrer Trennungen und Zusammensetzungen. Der Begriff der Gliederung ist ihre logische Function, so wie die des Denkens selbst. Wo also, vermöge der Schärfe des Sprachsinnes, in einem Volk die Sprache in ihrer ächten, geistigen und tönenden Eigenthümlichkeit empfunden wird, da wird dasselbe angeregt, bis zu ihren Elementen, den Grundlauten, vorzudringen, dieselben zu unterscheiden und zu bezeichnen, oder mit andren Worten, Buchstabenschrift zu erfinden, oder sich darbietende begierig zu ergreifen.

37- Richtigkeit der intellectuellen Ansicht der Sprache, von Lebendigkeit und Feinheit zeugende Bearbeitung ihrer Laute, und Buchstabenschrift erheischen und befördern sich daher gegenseitig, und vollenden, vereint, die Auffassung und Bildung der Sprache in ihrer ächten Eigenthümlichkeit. Jeder Mangel an einem dieser drei Punkte wird in ihrem Bau, oder ihrem Gebrauche fühlbar, und 
signification, ou bien, à tout le moins, ne sait pas amalgamer fermement les désignations grammaticales avec les mots, elle n'a affaire qu'à des touts sonores et n'est pas amenée à distinguer une articulation individuelle, comme elle le serait par l'apparition d'un même mot qui ne différerait que dans sa flexion. Par conséquent, autant la finesse et la vivacité du sens du langage conduisent à des formes grammaticales stables, autant celles-ci favorisent la reconnaissance de l'alphabet comme son, reconnaissance que suit rapidement l'invention ou l'usage fructueux de signes visibles. Car là où un alphabet s'allie à une langue encore imparfaite au plan grammatical, la flexion peut être formée par l'addition ou la modification de lettres individuelles, celle qui existe déjà peut être conservée de manière plus sûre et celle qui est encore à moitié en cours d'adjonction peut être isolée de manière plus nette ${ }^{18}$.

36- Mais l'écriture alphabétique agit sur la langue de manière encore beaucoup plus essentielle, bien que non aussi visiblement reconnaissable à des qualités individuelles, en ce qu'elle seule parachève la compréhension de l'articulation (Gliederung) de la langue et en répand le sentiment de manière plus générale. Car sans la différenciation, la détermination et la désignation des articulations (Articulationen) individuelles, les constituants élémentaires de la parole ne sont pas reconnus et la notion d'articulation (Gliederung) n'est pas appliquée à toute la langue. Il est de la plus grande importance d'appliquer intégralement tout concept qui se trouve en un objet, en général et partout, et encore plus là où l'objet, telle la langue, est totalement idéal et là où, en partie en même temps, en partie l'un après l'autre, l'instinct agit, le sentiment pressent et l'entendement comprend, et où la compréhension de l'entendement agit de nouveau en retour sur le sentiment et celui-ci, en le corrigeant, sur l'instinct. Les conséquences de l'absence $[\mathrm{V}, 122]$ de cela se font sentir largement au-delà de la partie restée inachevée, dans le cas des langues sans écriture alphabétique et sans traces visibles du besoin d'une telle écriture ; elles se font sentir non seulement dans la compréhension juste et entière de l'articulation des sons, mais également dans la façon entière dont ces langues sont structurées et employées. Mais l'articulation (Gliederung) est précisément l'essence du langage; il n'y a rien en lui qui ne puisse être partie et tout, l'efficacité de son activité continue repose sur la légèreté, l'exactitude et la concordance de ses séparations et compositions. Le concept de l'articulation (Gliederung) est sa fonction logique, tout comme celle de la pensée elle-même. Ainsi, là où une langue, grâce à l'acuité du sens du langage, est ressentie par un peuple dans ses véritables particularités spirituelles et sonores, le peuple sera amené à se frayer un chemin jusqu'à ses éléments, les sons fondamentaux, à différencier et à désigner ceux-ci ou, en d'autres mots, à inventer une écriture alphabétique ou à se saisir avidement de celle qui s'offre.

37- Par conséquent, la justesse de la vision intellectuelle de la langue, la vivacité et la finesse dans l'élaboration de ses sons et l'écriture alphabétique se réclament et se soutiennent mutuellement, et elles accomplissent, associées, la compréhension et la formation de la langue dans sa véritable particularité. Tout défaut de l'un de ces trois éléments sera perceptible dans la structure ou l'usage 
wo die natürliche Einwirkung der Dinge nicht durch besondre Umstände Abweichungen erfährt, da darf man sie vereint, und noch verbunden mit Festigkeit grammatischer Formen und rhythmischer Kunst anzutreffen hoffen.

38- Die hier gemachte Einschränkung beugt dem Bestreben vor, dasjenige, was sich theoretisch ergiebt, nun auch durch die Geschichte der Völker (sollte man es ihr auch aufdringen müssen) sogleich beweisen, oder voreilig widerlegen $\mathrm{zu}$ wollen. Darum darf aber die Entwicklung aus blossen Begriffen, wenn sie nur sonst richtig und vollständig ist, nicht unnütz genannt werden. Sie muss vielmehr, wo es nur irgend angeht, die Prüfung der Thatsachen begleiten, und ihr die Punkte der Untersuchung bestimmen helfen. Nach dem im Vorigen über den Zusammenhang des Sprachbaues mit der Buchstabenschrift Gesagten, werden erschöpfende Untersuchungen über die Verbreitung der letzteren nicht von der Geschichte der Sprachen selbst getrennt werden dürfen, und es wird überall auf die Frage ankommen: ob es die / [123] Beschaffenheit der Sprache, und die sich in ihr ausdrückende Sprachanlage der Nation, oder andre Umstände waren, welche wesentlich auf die Art der Erfindung oder Aneignung eines Alphabets einwirkten? inwiefern diese Entstehungsweise die Beschaffenheit desselben bestimmte oder veränderte, und welche Spuren es, bei allgemein gewordenem Gebrauch, in der Sprache zurückliess?

39- Es kann hier nicht meine Absicht seyn, nach der bis jetzt versuchten Entwicklung aus Ideen, noch in eine historische Untersuchung der Sprachen in Beziehung auf die Schriftmittel, deren sie sich bedienen, einzugehen. Nur um im Ganzen den behaupteten Zusammenhang zwischen der Buchstabenschrift und der Sprache auch an einer Thatsache zu erläutern, sey es mir erlaubt, diese Abhandlung mit einigen Betrachtungen über die Amerikanischen Sprachen in dieser Hinsicht zu beschliessen.

40- Man kann es als eine Thatsache annehmen, dass sich in keinem Theile Amerika's eine Spur einer Buchstabenschrift gezeigt hat, obgleich es bisweilen behauptet oder vermuthet worden ist. Unter den Mexicanischen Hieroglyphen findet sich zwar eine, zum Theil den Chinesischen Coua's ähnliche Gattung, die noch nicht genau erläutert ist, und dies, bei den wenigen vorhandnen Ueberbleibseln, auch wahrscheinlich nicht zulässt; wären aber darin auf irgend eine Weise Lautzeichen, so würden die Nachrichten, die wir über das Land und seine Geschichte besitzen, davon Spuren enthalten. Man könnte zwar hier die Einwendung machen, dass auch von Buchstabenzeichen in den Hieroglyphen das Alterthum schweigt. Allein hier ist der Fall durchaus anders. Dass Aegypten Buchstabenschrift besass, fieng nur in den allerneuesten Zeiten an bezweifelt zu werden, als man auch die demotische Schrift für Begriffszeichen erklärte, sonst gab es eine Menge von Zeugnissen, die es bewiesen, oder vermuthen liessen. Nur darüber stritt man, welche unter den Aegyptischen Schriftarten die alphabetische gewesen sey, oder suchte vielmehr den Sitz dieser bloss in der obengenannten demotischen.

41- Dass in Amerika ein Zustand früherer Cultur über die ältesten Anfänge der uns bekannten Geschichte hinaus untergegangen ist, beweist eine Reihe von 
de la langue, et là où l'action naturelle des choses ne subit point, du fait de circonstances particulières, de déviation, on peut espérer les trouver associées, et même unies avec solidité aux formes grammaticales et à l'art rythmique.

38- La réserve émise ici veut parer à la tentative de prouver immédiatement par l'histoire des peuples des conclusions théoriques (dût-on forcer l'histoire en ce sens) ou de les réfuter précipitamment. C'est pourquoi la pure réflexion conceptuelle, pour autant qu'elle soit par ailleurs juste et complète, ne doit pas être déclarée vaine. Elle doit plutôt, là où du moins c'est possible, accompagner l'examen des faits et aider les chercheurs à déterminer les points de l'enquête. Après ce qui vient d'être dit sur le rapport de la structure de la langue avec l'écriture alphabétique, les recherches exhaustives sur la diffusion de cette écriture ne doivent plus être séparées de l'histoire des langues et la question qui importera toujours sera la suivante : étaient-ce $[\mathrm{V}, 123]$ la nature particulière de la langue, et la disposition linguistique de la nation qui s'exprime en elle, ou d'autres circonstances qui ont essentiellement influé sur la sorte d'invention ou d'appropriation d'un alphabet ? dans quelle mesure ce mode de naissance a-t-il déterminé ou transformé la nature de l'alphabet et quelles traces ce dernier a-t-il laissées dans la langue quand son usage s'est généralisé ?

39- Après avoir tenté jusqu'à maintenant un développement à partir d'idées, mon intention ici ne peut être d'entrer en plus dans une étude historique des langues en relation avec les moyens d'écriture dont elles se servent. Mais pour illustrer globalement, ainsi qu'à l'aide d'un fait, le rapport postulé entre l'écriture alphabétique et la langue, qu'il me soit permis de conclure ce mémoire avec quelques considérations sur les langues américaines.

40- On peut admettre comme un fait qu'il ne s'est manifesté aucune trace d'écriture alphabétique dans quelque partie de l'Amérique que ce soit, même si on a de temps à autre affirmé ou présumé le contraire. Parmi les hiéroglyphes mexicains se trouve certes une écriture - en partie du même genre que les $\mathrm{Pa}$ kouas chinois ${ }^{19}$ - qui n'est pas encore parfaitement déchiffrée et qui, vu le peu de vestiges disponibles, ne peut vraisemblablement pas l'être; mais s'il y avait de quelque manière des signes phonétiques dans cette écriture, les informations que nous possédons sur le pays et son histoire en contiendraient des indices ${ }^{20}$. On pourrait certes formuler l'objection selon laquelle l'Antiquité est muette sur les signes alphabétiques dans les hiéroglyphes. Mais le cas ici est tout à fait différent. Que les Égyptiens aient possédé une écriture alphabétique, on n'a commencé à en douter que très récemment, quand l'écriture démotique ${ }^{21}$ a été déclarée écriture de concepts, sinon il y avait une foule de témoignages qui prouvaient ou laissaient supposer l'existence d'un alphabet. On se disputait seulement pour savoir laquelle, parmi les genres d'écritures égyptiennes, aurait été l'alphabétique, ou on cherchait plutôt le siège de cette dernière simplement dans l'écriture démotique mentionnée plus haut.

41- Qu'en Amérique, un état de culture plus ancien que les premiers commencements de l'histoire que nous connaissons ait disparu, cela est attesté par une 
Denkmälern, theils in Gebäuden, theils in künstlicher Bearbeitung des Erdbodens, die sich von den grossen Seen des nördlichen Theiles bis zur südlichsten Gränze Peru's erstrecken, von welchen ich zu einem andren Zweck theils aus der / [124] Reise meines Bruders, der ihre Gränzen, die Mittelpunkte dieser Civilisation, und den Strich, dem sie folgt, genau angiebt, und die Ursachen des letzteren sehr glücklich nachweist, theils aus andren Quellen, vorzüglich den Werken der ersten Eroberer, ein Verzeichniss zusammengetragen habe.

42- Meine Aufmerksamkeit bei der Untersuchung der Amerikanischen Sprachen ist daher immer zugleich darauf gerichtet gewesen, ob ihr Bau Spuren des Gebrauchs verloren gegangner Alphabete an sich trage? Ich habe jedoch nie dergleichen angetroffen; vielmehr ist der Organismus dieser Sprachen gerade von der Art, dass man, von den obigen allgemeinen Betrachtungen über den Zusammenhang der Sprache mit der Buchstabenschrift ausgehend, recht füglich begreifen kann, dass weder sie zur Erfindung eines Alphabets führten, noch auch, wenn sich ein solches dargeboten hätte, eine mehr als gleichgültige Aneignung desselben erfolgt seyn würde. Die Aufnahme der nach Amerika gekommenen Europaeischen Schrift beweist indess freilich hierfür nichts. Denn die unglücklichen Nationen wurden gleich so niedergedrückt, und ihre edelsten Stämme grossentheils dergestalt ausgerottet, dass an keine freie, wenigstens keine geistige nationelle Thätigkeit zu denken war. Einige Mexicaner ergriffen aber wirklich das neue Aufzeichnungsmittel, und hinterliessen Werke in der einheimischen Sprache.

43- Alle Vortheile des Gebrauchs der Buchstabenschrift beziehen sich, wie im Vorigen gezeigt ist, hauptsächlich auf die Form des Ausdrucks, und vermittelst dieser, auf die Entwicklung der Begriffe, und die Beschäftigung mit Ideen. Darin liegt ihre Wirkung, daraus entspringt das Bedürfniss nach ihr. Gerade die Form des Gedankens aber wird durch den Bau der Amerikanischen Sprachen, die zwar bei weitem nicht die bisweilen behauptete, aber doch, und eben hierin, eine auffallende Gleichartigkeit haben, nicht vorzüglich begünstigt, oft durchaus vernachlässigt, und die Amerikanischen Volksstämme standen, auch bei der Eroberung, und in ihren blühendsten Reichen, nicht auf der Stufe, wo im Menschen der Gedanke, als überall herrschend, hervortritt.

44- An die Seltenheit und zum Theil den gänzlichen Mangel solcher grammatischer Bezeichnungen, die man ächte grammatische Formen nennen könnte, will ich hier nur im Vorbeigehen noch einmal erinnern. Aber ich glaube mich nicht zu irren, wenn ich auch die nur durch höchst seltne Abweichungen unter- / [125] brochne strenge und einförmige Analogie dieser Sprachen, die Häufung aller durch einen Begriff gegebnen Nebenbestimmungen, auch da, wo ihre Erwähnung nicht nothwendig ist, die vorherrschende Neigung $\mathrm{zu}$ dem besondren Ausdruck, statt des allgemeineren, hierher zähle. Der dauernde Gebrauch einer alphabetischen Schrift würde, wie es mir scheint, nicht nur diese Dinge abgeändert oder umgestaltet haben, sondern lebendigere nationelle Geistigkeit hätte sich auch dieser unbehülflichen Fesseln zu entledigen gewusst, 
série de monuments - en partie des bâtiments, en partie les résultats d'un traitement du sol fait avec art ${ }^{22}$ - qui s'étendent depuis les Grands Lacs de la partie nordique du continent jusqu'au sud de la frontière du Pérou, monuments dont $\mathrm{j}$ ' ai fait dans un autre but un relevé, en partie en me servant du [V, 124] voyage de mon frère ${ }^{23}$ - qui indique avec exactitude les frontières, les centres d'intérêts de cette civilisation et le parcours qu'elle suit, et montre très bien les origines de ce parcours -, en partie en me servant d'autres sources, surtout des œuvres des premiers conquérants.

42- En faisant des recherches sur les langues américaines, $\mathrm{j}$ 'ai toujours essayé par conséquent de voir en même temps si leur structure portait des traces de l'usage d'un alphabet perdu. Je n'ai cependant jamais trouvé quoique ce soit de semblable ; au contraire, l'organisme de ces langues est précisément d'une nature telle que l'on peut à juste titre présumer, en partant des observations générales faites plus haut sur le rapport de la langue avec l'écriture alphabétique, qu'elles ne conduisirent pas à l'invention d'un alphabet, et également que, si un tel alphabet s'était offert, il en aurait résulté une appropriation plus qu'indifférente. Il faut dire pourtant que la réception de l'écriture européenne en Amérique ne prouve rien dans ce cas. Car ces nations malheureuses furent tout de suite tellement accablées, et leurs tribus les plus nobles pour une si grande part exterminées, que toute activité libre, du moins toute activité spirituelle nationale, était exclue. Quelques Mexicains embrassèrent toutefois réellement le nouveau mode de notation et laissèrent des œuvres dans leur langue autochtone.

43- Tous les avantages de l'emploi d'une écriture alphabétique se rapportent, comme on l'a montré plus tôt, avant tout à la forme de l'expression et, au moyen de celle-ci, au développement des concepts et au travail sur les idées. C'est en cela que réside son effet et c'est de cela que naît le besoin d'une telle écriture. Mais justement la forme de la pensée ne sera pas très bien favorisée, sera plutôt négligée, par la structure des langues américaines, lesquelles n'ont certes pas, loin s'en faut, la similitude qu'on leur a parfois prêtée, mais dont la structure, elle, présente bien pourtant une similitude frappante ${ }^{24}$, et les peuplades américaines, même lors de la conquête, et dans leurs empires les plus florissants, ne se trouvaient pas au niveau où, dans l'être humain, la pensée manifeste son règne partout $^{25}$.

44- La rareté et, dans certains cas, l'absence totale de ces désignations grammaticales que l'on peut qualifier de formes grammaticales authentiques ${ }^{26}$, je ne veux les évoquer ici qu'en passant. Mais je ne crois pas me tromper quand je recense ici l'analogie rigoureuse et uniforme de ces langues américaines (qui est $[\mathrm{V}, 125]$ interrompue seulement par de très rares exceptions), le cumul de déterminations accessoires données par un concept (même là où leur mention n'est pas nécessaire), la tendance dominante à l'expression particulière au lieu de la plus générale. L'usage continu d'une écriture alphabétique aurait, il me semble, non seulement modifié ou réorganisé ces choses, mais une spiritualité nationale plus vive aurait aussi su se débarrasser de ces entraves maladroites, elle aurait compris les concepts dans leur généralité, utilisé l'articulation 
die Begriffe in ihrer Allgemeinheit aufgefasst, die in dem Gedanken und der Sprache liegende Gliederung energischer und angemessner angewandt, und den Drang gefühlt, das ängstliche Aufbewahren der Sprache im Gedächtniss durch Zeichen für das Auge zu sichern, damit die Reflexion ruhiger über ihr walten, und der Gedanke sich in festeren, aber mannigfaltiger wechselnden und freieren Formen bewegen könne. Denn wenn die Buchstabenschrift nicht die Bevölkerung Amerika's begleitet hatte (insofern man nemlich überhaupt eine von der Fremde her annimmt), so waren die Amerikanischen Nationen wohl nur auf eigne Erfindung derselben zurückgewiesen, und da diese mit ungemeinen Schwierigkeiten verbunden ist, so mag die lange Entbehrung einer Buchstabenschrift nicht unbedeutend auf den Bau ihrer Sprachen eingewirkt haben. Diese Einwirkung konnte auch noch dadurch besonders modificirt werden, dass auch die Gattung der Schrift, welche einige Amerikanische Volker wirklich besassen, nicht von der Art war, bedeutenden Einfluss auf die Sprache und das Gedankensystem auszuüben.

45- Ich berühre jedoch dies nur im Vorbeigehn, da, um wirklich darauf fussen zu können, es eine Vergleichung der Sprachen Amerika's mit denen der Völkerstämme andrer Welttheile, die sich gleichfalls keiner Schriftzeichen bedienen, und mit der Chinesischen, der wenigstens alphabetische fremd sind, nothwendig machen würde, zu welcher hier nicht der Ort ist.

46- Dagegen liegt es den hier anzustellenden Betrachtungen näher, und leuchtet von selbst ein, dass lange Entbehrung der Schrift die regelmässige Einförmigkeit des Sprachbaues, die man fälschlich für einen Vorzug hält, befördert. Abweichungen werden dem Gedächtniss mühevoller aufzubewahren, vorzüglich wenn noch nicht hinreichendes Nachdenken über die Sprache erwacht ist, um ihre inneren Gründe zu entdecken und zu würdigen, oder nicht genug Forschungsgeist, ihre bloss geschichtlichen aufzusuchen. / [126] Das Vorherrschen des Gedächtnisses gewöhnt auch die Seele an das Hervorbringen der Gedanken in möglichst gleichem Gepräge, und der auf genaue Sprachuntersuchung gerichteten Aufmerksamkeit endlich sind die Fälle nicht fremd, wo die Schrift selbst, das Aneinanderreihen der Buchstaben, Abkürzungen und Veränderungen hervorbringt.

47- Man darf hiermit nicht verwechslen, dass die Schrift den Formen auch mehr Festigkeit, und dadurch in andrer Rücksicht mehr Gleichförmigkeit giebt. Dadurch wirkt sie vorzüglich nur der Spaltung in zu vielfältige Mundarten entgegen, und schwerlich würden sich, bei anhaltendem Schriftgebrauch, die den meisten Amerikanischen Sprachen eignen Verschiedenheiten der Ausdrücke der Männer und Weiber, Kinder und Erwachsnen, Vornehmen und Geringen erhalten haben. In demselben Stamm und derselben Classe zeigen sonst gerade die Amerikanischen Nationen ein bewunderungswürdiges Festhalten der gleichen Formen durch die blosse Ueberlieferung. Man hat Gelegenheit, dies durch die Vergleichung der Schriften der in die ersten Zeiten der Europaeischen Ansiedelungen fallenden Missionarien mit der heutigen Art zu sprechen zu bemerken. Vorzüglich bietet sich dieselbe bei den Nordamerikanischen 
(Gliederung) qui réside dans la pensée et dans la langue de manière plus énergique et pertinente et éprouvé le besoin de garantir par des signes pour l'œil la conservation anxieuse de la langue dans la mémoire, pour que la réflexion puisse régner plus calmement sur la langue et que la pensée puisse se mouvoir dans des formes plus stables, mais aussi plus diversement changeantes et libres. Car si l'écriture alphabétique n'avait pas accompagné le peuplement de l'Amérique (dans la mesure où on suppose généralement un peuplement qui soit venu de l'étranger), les nations américaines ne pouvaient s'en remettre qu'à leur propre invention d'une telle écriture, et parce que cette invention est liée à de prodigieuses difficultés, la longue privation d'une écriture alphabétique a pu avoir un effet non négligeable sur la structure de leurs langues. Cet effet pouvait aussi subir des modifications particulières du fait que le genre d'écriture réellement utilisé par quelques peuples américains n'était pas non plus d'une sorte à exercer une influence significative sur la langue et le système des pensées.

45- Je n'effleure cela toutefois qu'en passant, parce que, pour pouvoir vraiment être fondées, ces hypothèses exigeraient une comparaison des langues d'Amérique avec celles des peuplades d'autres parties du monde qui de même ne se servent d'aucun signe d'écriture et avec la langue chinoise, à laquelle les signes alphabétiques sont pour le moins étrangers, comparaison qui n'a pas sa place ici.

46- Par contre, ce qui paraît davantage ressortir des considérations auxquelles on se livre ici et qui saute aux yeux, c'est que la longue privation d'une écriture favorise l'uniformité régulière de la structure de la langue, que l'on prend à tort pour un avantage. Les exceptions sont plus pénibles à retenir pour la mémoire, en particulier quand il n'y a pas encore de réflexion suffisante sur la langue pour en découvrir et apprécier les fondements internes, ou bien pas assez d'esprit scientifique pour en chercher les simples causes historiques. [V, 126] La prédominance de la mémoire habitue aussi l'âme à la production des pensées dans une empreinte qui soit autant que possible constante. Et les cas où l'écriture ellemême produit la succession des lettres, ainsi que des abrègements et des transformations, ne sont pas étrangers enfin à qui fixe son attention sur l'analyse précise du langage.

47- On ne doit pas confondre avec cela le fait que l'écriture donne aussi aux formes plus de stabilité et ainsi, sous un autre rapport, plus de régularité. Ce faisant elle agit d'abord seulement contre la division en parlers trop variés et les divergences, propres à la plupart des langues américaines, dans les expressions employées par les hommes et les femmes, les enfants et les adultes, les nobles et le peuple se seraient difficilement maintenues avec un emploi continu de l'écriture. Par ailleurs, dans la même tribu et la même classe, les nations américaines témoignent justement d'une admirable conservation des mêmes formes par la simple tradition. On peut observer cela en comparant les écrits des missionnaires des premiers temps de la colonisation européenne avec la manière actuelle de parler. Celle-ci s'offre à nous principalement dans les tribus nord- 
Stämmen dar, da man sich in den Vereinigten Staaten (und jetzt leider nur dort) auf eine höchst beifallswürdige Weise um die Sprache und das Schicksal der Eingebornen bemüht. Es wäre indess sehr zu wünschen, dass sich die Aufmerksamkeit noch bestimmter auf diese Vergleichung derselben Mundarten in verschiednen Zeiten richtete. Die durch die Schrift hervorgebrachte Festigkeit ist daher mehr ein Verallgemeinern der Sprache, welches nach und nach in die Bildung eines eignen Dialects übergeht, und sehr verschieden von der Durchführung Einer Regel durch eine Menge zwar ähnlicher, doch, Begriff und Ton genau beachtet, nicht immer ganz gleicher Fälle, von der wir oben redeten.

48- Alles hier Gesagte findet auch auf das Zusammenhäufen zu vieler Bestimmungen in Einer Form Anwendung, und wenn man den Gründen tiefer nachgeht, so hängen die hier erwähnten Erscheinungen sämmtlich von der mehr, oder weniger stark und eigenthümlich auf die Sprache gerichteten Regsamkeit des Geistes ab, von welcher die Schrift zugleich Beweis und befördernde Ursach ist. Wo diese Regsamkeit mangelt, zeigt es sich in dem unvollkommneren Sprachbau; wo sie herrscht, erfährt dieser eine / [127] heilsame Umformung, oder kommt von Anfang an nicht zum Vorschein. Mit dem einen und andren Zustande aber ist die Schrift, das Bedürfniss nach ihr, die Gleichgültigkeit gegen sie, in beständiger Verbindung.

49- Bei der Aufzählung der Ursachen der Eigenthümlichkeit der Amerikanischen Sprachen darf man aber auch die oben erwähnte Gleichartigkeit derselben, so wie die Absonderung Amerika's von den übrigen Welttheilen nicht vergessen. Selbst wo entschieden verschiedne Sprachen ganz nahe bei einander waren, wie im heutigen Neu-Spanien, habe ich in ihrem Bau nie eine belebende oder gestaltende Einwirkung der einen auf die andre an irgend einer sichren Spur bemerken können. Die Sprachen vorzüglich gewinnen aber an Kraft, Reichthum und Gestaltung durch das Zusammenstossen grosser und selbst contrastirender Verschiedenheit da auf diesem Wege ein reicherer Gehalt menschlichen Daseyns, schon zu Sprache geformt, in sie übergeht. Denn dies nur ist ihr realer Gewinn, der in ihnen, wie in der Natur, aus der Fülle schaffender Kräfte entsteht, ohne dass der Verstand die Art dieses Schaffens ergründen kann, aus der Anschauung, der Einbildungskraft, dem Gefühl. Nur von diesen hat sie Stoff und Bereicherung zu erwarten; von der Bearbeitung durch den Verstand, wenn dieselbe darüber hinausgeht, dem Stoff seine volle Geltung in klarem und bestimmtem Denken zu verschaffen, eher Trockenheit und Dürftigkeit zu fürchten. Die Schrift nun kann sich leichter verbreiten, selbst leichter entstehen, wo verschiedne Völkereigenthümlichkeit sich lebendig gegeneinander bewegt; einmal entstanden und ausgebildet, kann sie aber auch, wie die logische Bearbeitung, zu der sie am mächtigsten mitwirkt, der Lebendigkeit der Sprache, und ihrer Einwirkung auf den Geist nachtheilig werden.

50- Bei den Amerikanischen Völkerstämmen lag aber dasjenige, was sie, da ihnen Buchstabenschrift einmal nicht von aussen zugekommen war, von derselben fern hielt, freilich vorzüglich noch im Mangel geistiger Bildung, ja 
américaines, parce qu'aux États-Unis (et maintenant juste là, malheureusement), on se préoccupe de la langue et du destin des indigènes d'une manière qui mérite une grande approbation ${ }^{27}$. Il serait très souhaitable que l'attention se fixe de manière encore plus déterminée sur la comparaison des mêmes parlers à différentes époques. La stabilité apportée par l'écriture est par conséquent plus une généralisation de la langue, généralisation qui peu à peu se mue en la formation d'un dialecte propre et elle est très différente de l'application d'une seule règle à une foule de cas certes semblables, mais qui, compte tenu justement du concept et du son, ne sont pas toujours entièrement pareils. De cela nous avons parlé plus haut.

48- Tout ce qui a été dit ici s'applique également à l'accumulation de nombreuses déterminations dans une seule forme, et quand on explore plus en profondeur les causes, on voit que les phénomènes mentionnés ici dépendent dans leur ensemble du fait que la vivacité de l'esprit soit plus ou moins fortement et particulièrement dirigée vers la langue, vivacité dont l'écriture est à la fois preuve, cause et soutien. Là où une telle vivacité fait défaut, il en résulte une structure imparfaite de la langue ; là où elle règne, la structure imparfaite subit une $[\mathrm{V}, 127]$ transformation salutaire, ou encore, elle n'apparaît pas du tout. Mais l'écriture - le besoin que l'on a d'elle, l'indifférence qu'on éprouve à son endroit - est en liaison constante avec l'un et l'autre de ces états.

49- En énumérant les causes de la particularité des langues américaines, on ne doit cependant pas oublier la similitude de celles-ci, déjà évoquée, de même que l'isolement de l'Amérique d'avec le reste du monde. Même là où des langues clairement variées se trouvaient très proches l'une de l'autre, comme dans l'actuelle Nouvelle-Espagne, je n'ai jamais pu observer, dans quelque trace sûre, une influence vivifiante ou organisatrice de l'une sur l'autre. Pourtant, les langues gagnent admirablement en force, en richesse et en organisation dans le heurt de leur grande et même contrastante diversité parce que, de cette manière, un contenu plus riche de l'existence humaine déjà modelé en langue passe en elles. Car leur seul gain réel est celui qui, comme dans la nature, naît en elles de la profusion des forces créatrices de l'intuition, de l'imagination, du sentiment, sans que l'entendement puisse sonder la nature de cette créativité. De ces forces créatrices seules la langue peut espérer matière et enrichissement; de l'élaboration par l'entendement - si celle-ci outrepasse son rôle, soit donner à la matière sa pleine valeur dans une pensée claire et définie -, la langue doit plutôt redouter la sécheresse et la pauvreté. L'écriture peut se diffuser plus facilement, même naître plus facilement là où diverses particularités nationales se heurtent vivement les unes aux autres; une fois née et développée, l'écriture peut cependant aussi, comme l'élaboration logique à laquelle elle contribue très puissamment, devenir préjudiciable à la vivacité de la langue et à son action sur l'esprit.

50- Ce qui a tenu les peuplades américaines loin d'une écriture alphabétique cependant, puisque celle-ci ne leur est même pas parvenue de l'extérieur, réside en fait surtout dans le manque de culture de l'esprit, d'orientation intellectuelle 
nur intellectueller Richtung überhaupt. Davon geben die Mexicaner ein auffallendes Beispiel. Sie besassen, wie die Aegyptier, Hieroglyphen-Bilder und Schrift, machten aber nie die beiden wichtigen Schritte, wodurch jenes Volk der alten Welt gleich seine tiefe Geistigkeit bewies, die Schrift von dem Bilde zu sondern, und das Bild als sinniges Symbol zu behandeln, Schritte, welche, aus der geistigen Individualität des / [128] Volks entspringend, der ganzen Aegyptischen Schrift ihre bleibende Form gaben, und die man, wie es mir scheint, nicht als bloss stufenweis fortgehende Entwicklung des Gebrauchs der Bilderschrift ansehen darf, sondern die geistigen Funken gleichen, die, plötzlich umgestaltend, in einer Nation oder einem Individuum sprühen. Die Mexicanische Hieroglyphik gelangte ebensowenig zur Kunstform. Und doch scheinen mir die Mexicaner unter den uns bekannt gewordnen Amerikanischen Nationen an Charakter und Geist die vorzüglichsten zu seyn, und namentlich die Peruaner weit übertroffen zu haben, so wie ich auch glaube, die Vorzüge ihrer Sprache vor der Peruanischen beweisen zu können. Die Grässlichkeit ihrer Menschenopfer zeigt sie allerdings in einer unglaublich rohen und abschreckenden Gestalt. Allein die kalte Politik, mit welcher die Peruaner, nach blossen Einfällen ihrer Regenten, unter dem Schein weiser Bevormundung, ganze Nationen ihren Wohnsitzen entrissen, und blutige Kriege führten, um, soweit sie zu reichen vermochten, den Völkern das Gepräge ihrer mönchischen Einförmigkeit aufzudrücken, ist kaum weniger grausam zu nennen. In der Mexicanischen Geschichte ist regere und individuellere Bewegung, die, wenn auch die Leidenschaften Rohheit verrathen, sich doch, bei hinzukommender Bildung, zu höherer Geistigkeit erhebt. Die Ansiedlung der Mexicaner, die Reihe ihrer Kämpfe mit ihren Nachbarn, die siegreiche Erweiterung ihres Reichs erinnert an die Römische Geschichte. Von dem Gebrauch ihrer Sprache in Dichtkunst und Beredsamkeit lässt sich nicht genau urtheilen, da, was auch von Reden, im Rath und bei häuslichen Veranlassungen, in den Schriftstellern vorkommt, schwerlich hinlänglich treu aufgefasst ist. Allein es lässt sich sehr wohl denken, dass, vorzüglich in den politischen, dem Ausdruck weder Scharfsinn, noch Feuer, noch hinreissende Gewalt jeder Empfindung gefehlt haben mag. Findet sich doch dies alles noch in unsren Tagen in den Reden der Häuptlinge der Nord-Amerikanischen wilden Horden, deren Aechtheit nicht zu bezweifeln scheint, und wo diese Vorzüge gerade nicht können aus dem Umgange mit Europaeern abgeleitet werden. Da Alles, was den Menschen bewegt, in seine Sprache übergeht, so muss man wohl die Stärke und Eigenthümlichkeit der Empfindungsweise und des Charakters im Leben überhaupt von der intellectuellen Richtung und der Neigung zu Ideen unterscheiden. Beides strahlt in dem Ausdruck wieder, aber auf die Gestaltung und den Bau der Sprache kann [129] doch, ohne das letztere, nicht mächtig und dauernd gewirkt werden.

51- Es ist sehr wahrscheinlich, dass, wenn auch das Mexicanische und Peruanische Reich noch Jahrhunderte hindurch unerobert von Fremden bestanden hätte, diese Nationen doch nicht würden aus sich selbst zur 
en général. Les Mexicains fournissent de cela un exemple remarquable. Ils possédaient, comme les Égyptiens, une écriture et des images hiéroglyphiques, mais n'ont jamais fait les deux pas importants grâce auxquels le peuple de l'Ancien Monde a justement prouvé sa profonde spiritualité, à savoir séparer l'écriture de l'image et traiter l'image comme un symbole doté de sens, deux pas qui, prenant leur source dans $[\mathrm{V}, 128]$ l'individualité spirituelle du peuple, ont donné à toute l'écriture égyptienne sa forme stable et qu'on ne devrait pas, il me semble, considérer comme un simple développement graduel et continu de l'usage de l'écriture en images, mais plutôt voir comme des étincelles d'esprit qui jaillissent dans une nation ou un individu, en apportant des transformations soudaines ${ }^{28}$. La hiéroglyphique mexicaine n'a pas non plus accédé à la forme artistique. Et pourtant, parmi les nations américaines qui nous sont devenues familières, les Mexicains me semblent être ceux qui sont les plus remarquables par le caractère et l'esprit ; ils ont à vrai dire dépassé de loin les Péruviens, si bien que je crois pouvoir prouver les avantages de leur langue par rapport au péruvien. L'horreur de leurs sacrifices humains les montrent dans une forme incroyablement brutale et terrifiante. Mais la froide politique, en vertu de laquelle les Péruviens, suivant de simples lubies de leurs souverains et sous prétexte d'une tutelle plus avisée, arrachèrent à des nations entières leurs domiciles et menèrent des guerres sanglantes pour, aussi loin qu'ils pouvaient aller, imposer aux peuples l'empreinte de leur uniformité monacale, mérite à peine moins d'être qualifiée d'atroce. Dans l'histoire mexicaine, il y a un mouvement plus individuel et plus vif qui, même si les passions trahissent de la brutalité, s'élève cependant à une spiritualité plus élevée, étant donné la culture qui s'y ajoute. L'établissement des Mexicains, la succession de leurs combats avec leurs voisins, l'élargissement triomphal de leur empire rappellent l'histoire romaine. De l'emploi de leur langue dans la poésie ou l'éloquence, on ne peut pas facilement juger, parce que même ce que la plume des écrivains révèle des discours faits en conseil et lors d'affaires privées n'est pas saisi de manière suffisamment fidèle. Mais l'on peut très bien penser que l'expression, en particulier dans les discours politiques, n'a pu manquer ni de finesse, ni de feu, ni de la force entraînante de tout sentiment. On trouve du moins encore toutes ces qualités de nos jours dans les discours des chefs des tribus ${ }^{29}$, chez les sauvages d'Amérique du Nord, discours dont l'authenticité n'est pas à mettre en doute et où ces qualités ne peuvent justement pas provenir de leurs fréquentations avec des Européens. Comme tout ce qui émeut l'homme se transmet à sa langue, on doit sans doute distinguer la force et la particularité de la sensibilité et du caractère dans la vie en général, de l'orientation intellectuelle et de l'inclination aux idées. Toutes deux se reflètent dans l'expression, mais sans la dernière, il ne peut $[\mathrm{V}, 129]$ y avoir d'effet puissant et durable sur la formation et la structure de la langue.

51- Il est très probable que, même si les royaumes mexicains et péruviens étaient demeurés pendant des siècles sans être conquis par des étrangers, ces nations ne seraient pas arrivées d'elles-mêmes à l'écriture alphabétique. L'écriture en images et les cordelettes à nœuds, que les deux nations possédaient 
Buchstabenschrift gelangt seyn. Die Bilderschrift und die Knotenschnüre, welche beide besassen, von welchen aber, aus noch nicht gehörig klar gewordenen Ursachen, jene bei den Mexicanern, diese bei den Peruanern ausschliesslich im Staats- und eigentlichen Nationalgebrauch blieben, erfüllten die äussren Zwecke der Gedanken-Aufzeichnung, und ein innres Bedürfniss nach vollkommneren Mitteln wäre schwerlich erwacht.

52- Ueber die Knotenschnüre, die auch in andren Gegenden Amerika's, ausserhalb Peru und Mexico, üblich waren, und die auf Vermuthungen eines Zusammenhanges der Bevölkerung Amerika's mit China, so wie die Hieroglyphen mit Aegypten geführt haben, werde ich an einem andren Orte die Nachrichten, die sich von ihnen finden, zusammenstellen. Sie sind allerdings sehr mangelhaft, aber doch hinreichend, einen bestimmteren und genaueren Begriff von dieser Gattung von Zeichen zu geben, als man durch Robertson's, und andrer neuerer Schriftsteller Berichte erhält. Ihre Bedeutung lag in der Zahl ihrer Knoten, der Verschiedenheit ihrer Farben, und vermuthlich auch der Art ihrer Verschlingung. Diese Bedeutung war jedoch wohl nicht überall dieselbe, sondern verschieden nach den Gegenständen, und man musste vermuthlich, um sie zu erkennen, wissen, von wem die Mittheilung herrührte, und was sie betraf. Denn es waren auch der Aufbewahrung dieser Schnüre, nach der Verschiedenheit der Verwaltungszweige, verschiedne Beamte vorgesetzt. Ihre Entzifferung endlich war künstlich, und sie bedurften eigener Ausleger. Sie scheinen daher im Allgemeinen mit den Kerbstöcken in Eine Classe zu gehören, allein durch einen Grad sehr hoher Vervollkommnung künstliche Mittel, zuerst, mnemonisch, der Erinnerung, hernach, wenn der Schlüssel des Zusammenhanges der Zeichen mit dem Bezeichneten bekannt war, der Mittheilung gewesen zu seyn. Es bleibt nur zweifelhaft, in welchem Grade sie sich von subjectiven Verabredungen für bestimmte und genau bedingte Fälle zu wirklichen Gedankenzeichen erhoben. Dass sie [130] beides zugleich waren, ist offenbar, da z. B. in denjenigen, durch welche die Richter von der Art und Menge der verhängten Bestrafungen Nachricht gaben, die Farben der Schnüre die Verbrechen, die Knoten die Arten der Strafen andeuteten. Ob aber in ihnen auch ein allgemeinerer Gedankenausdruck möglich war, ist nicht klar, und sehr zu bezweifeln, da die Verschlingung auch farbiger Schnüre keine hinlängliche Mannigfaltigkeit von Zeichen zu gewähren scheint.

53- Dagegen lagen in dieser Kunst der Knotenschnüre vielleicht besondre Methoden der Gedächtnisshülfe oder Mnemonik, wie sie auch dem classischen Alterthum nicht fremd waren. Diese scheinen bei den Peruanern wirklich üblich gewesen zu seyn. Denn es wird erzählt, dass Kinder, um ihnen von den Spaniern mitgetheilte Gebetsformeln zu behalten, farbige Steine an einander reiheten, also, nur mit andren Gegenständen, ein den Knotenschnüren ähnliches Verfahren beobachteten. In dieser Voraussetzung waren die Knotenschnüre allerdings Schrift im weitläuftigeren Sinne des Worts, entfernten sich doch aber sehr von diesem Begriff, da das Verständniss bei der Mittheilung in der 
- lesquelles cependant ont réservé exclusivement l'une des formes, les images chez les Mexicains et les cordelettes chez les Péruviens, à un emploi étatique ou national proprement dit, cela pour des raisons qu'on n'a pas encore convenablement éclaircies -, ces écritures remplissaient la fonction extérieure de notation des pensées et un besoin intérieur de moyens plus parfaits n'aurait guère pu être éveillé.

52- Dans un autre lieu, je rassemblerai les informations que l'on trouve au sujet des cordelettes à nœuds ${ }^{30}$, qui étaient aussi utilisées dans d'autres régions de l'Amérique que le Pérou et le Mexique et qui conduisent aux hypothèses d'un rapport du peuplement de l'Amérique avec la Chine, comme c'est le cas pour les hiéroglyphes avec l'Égypte. Ces informations sont, à vrai dire, très lacunaires, mais quand même suffisantes pour donner une notion de ce genre de signes plus déterminée et précise que celle que l'on trouve dans les récits de Robertson ${ }^{31}$ et d'autres écrivains plus récents. La signification de ces cordelettes résidait dans le nombre de leurs nœuds, la diversité de leurs couleurs et vraisemblablement aussi la forme de leur entrelacement. Mais cette signification n'était sans doute pas toujours la même, elle variait selon les sujets abordés et on devait vraisemblablement savoir, pour la saisir, de qui provenait la communication et sur quoi elle portait. Aussi y avait-il différents fonctionnaires affectés à la conservation de ces cordelettes, selon les diverses branches de l'administration. Le déchiffrage des cordelettes était en fin de compte un art et elles exigeaient leurs propres interprètes. En général, elles semblent par conséquent appartenir à une même classe que les bâtons de comptage, c'est-à-dire être des moyens artificiels (mais caractérisés par un degré de perfectionnement bien supérieur) de mémorisation d'abord et de communication ensuite, quand la clé du rapport des signes avec le signifié était connue. Mais dans quelle mesure ces cordelettes dépassent le stade d'arrangements subjectifs faits dans des cas particuliers et précisément déterminés, pour devenir de véritables signes de pensées, cela demeure incertain. Qu'elles aient été $[\mathrm{V}, 130]$ les deux en même temps est évident, parce que, par exemple, dans les cordelettes que le juge employait pour informer l'audience de la nature et du nombre de peines décrétées, la couleur indiquait les crimes et les nœuds la nature des peines. Quant à savoir si une expression plus générale des pensées pouvait être rendue par ces signes, ce n'est pas clair et c'est très incertain, parce que l'entrelacement de cordelettes, même colorées, ne semble pas pouvoir offrir une variété suffisante de signes.

53- En revanche on trouvait peut-être dans cet art des cordelettes à nœuds des méthodes particulières de mémorisation, des mnémoniques, qui n'étaient pas étrangères non plus à l'Antiquité classique. De telles méthodes semblent avoir été courantes en effet chez les Péruviens. Car on raconte que des enfants, pour retenir des formules de prières leur ayant été enseignées par les Espagnols, alignaient des pierres de couleurs les unes à côté des autres; par conséquent, ils employaient un procédé semblable à celui des cordelettes, mais avec d'autres objets. Dans ces conditions, les cordelettes à nœuds étaient bien sûr une écriture au sens élargi du mot, mais s'éloignaient par contre beaucoup du concept 
Entfernung auf der Kenntniss der äusseren Umstände beruhte, und wo sie zu geschichtlicher Ueberlieferung dienten, dem Gedächtniss doch die hauptsächlichste Arbeit blieb, der die Zeichen nur zu Hülfe kamen, die Fortpflanzung mündlicher Erklärung hinzutreten musste, und die Zeichen nicht eigentlich und vollständig (wie es die Schrift, wenn nur der Schlüssel ihrer Bedeutung gegeben ist, doch thun soll) den Gedanken durch sich selbst aufbewahrten.

54- Mit Sicherheit lässt sich jedoch hierüber kein Urtheil fällen. Ich bin auch nur darum in die vermuthliche Beschaffenheit dieser Knotenschnüre, von welchen sich noch im vorigen Jahrhundert einer (aber ein Mexicanischer) in der Boturinischen Sammlung befand, eingegangen, um zu zeigen, auf welche Weise die Völker Amerika's die doppelte Art der Zeichen kannten, zu welcher alle Schrift, wie sie seyn mag, gehört, die durch sich selbst verständliche der Bilder, und die durch willkührlich für das Gedächtniss gebildete Ideenverknüpfung, wo das Zeichen durch etwas Drittes (den Schlüssel der Bezeichnung) an das Bezeichnete erinnert. Die Unterscheidung dieser beiden Gattungen, die da in einander übergehen, wo die allegorisirende Bilderschrift auch ihre unmittelbare Verständlichkeit aufgiebt, und die, der Masse nach, und im [131] Fortschreiten willkührlich scheinenden Zeichen zum Theil ursprünglich Bilder waren, ist aber, und gerade in Rücksicht auf die Sprache, von erheblicher Wichtigkeit, wie man an der Mexicanischen und Peruanischen zeigen kann.

55- Die Mexicanischen Hieroglyphen hatten einen nicht geringen Grad der Vollkommenheit erreicht; sie bewahrten offenbar den Gedanken durch sich selbst, da sie noch heute verständlich sind, sie unterschieden sich auch bisweilen deutlich von blossen Bildern. Denn wenn auch z. B. der Begriff der Eroberung in ihnen meistentheils durch den Kampf zweier Krieger vorgestellt wird, so findet man doch auch den sitzenden König mit seinem Namenszeichen, dann Waffen, als Trophaeen gebildet, und das Sinnbild der eroberten Stadt, welches zusammengenommen die deutliche Phrase: der König eroberte die Stadt, und eine viel bestimmter ausgedruckte ist, als die berühmte Saitische Inschrift, die als die einzige angeführt zu werden pflegt, wo sich in dem Zeugniss des Alterthums zugleich Bedeutung und Zeichen erhalten haben. Man sieht auch aus dem eben Gesagten, dass es nicht an Mitteln fehlte auch Namen zu schreiben, und man daher auf dem Wege war Lautzeichen in der Art der Chinesischen zu besitzen. Dennoch ist sehr zu bezweifeln, ob die Mexicanische Hieroglyphik jemals wahre Schrift geworden ist.

56- Denn wahre Schrift kann man nur diejenige nennen, welche bestimmte Wörter in bestimmter Folge andeutet, was, auch ohne Buchstaben, durch Begriffszeichen, und selbst durch Bilder möglich ist. Nennt man dagegen Schrift im weitläuftigsten Verstande jede Gedanken-Mittheilung, die durch Laute geschieht, d.h. bei welcher der Schreibende sich Worte denkt, und welche der Lesende in Worte, wenn gleich nicht in dieselben, übersetzt (eine Bestimmung, ohne die es gar keine Gränze zwischen Bild und Schrift geben würde), so liegt 
d'écriture, parce que, lors de la communication à distance, la compréhension reposait sur la connaissance de circonstances extérieures et là où les cordelettes ont servi à la transmission historique, la mémoire faisait encore l'essentiel du travail, les signes ne faisaient que lui venir en aide, la diffusion d'explications orales devait s'y ajouter, et les signes ne pouvaient réellement et entièrement conserver les pensées par eux-mêmes (comme une écriture, pour peu que la clé de sa signification soit donnée, doit pourtant le faire).

54- À ce sujet on ne peut cependant rendre aucun jugement avec certitude ${ }^{32}$. Je n'ai abordé la nature probable de ces cordelettes à nœuds, dont on trouvait encore au siècle dernier un exemplaire (mais mexicain) dans la collection Boturini, que pour montrer de quelle manière les peuples d'Amérique connaissaient la double nature des signes à laquelle toute écriture, quelle qu'elle soit, appartient, celle des images qui est compréhensible en elle-même et celle que l'on comprend à travers des liaisons d'idées construites arbitrairement pour la mémoire, où le signe, à l'aide d'un élément tiers (la clé de la désignation), évoque le signifié. La distinction entre ces deux genres d'écriture - qui se sont fondus là où l'écriture en images, allégorisante, abandonne aussi sa compréhensibilité immédiate et là où l'écriture de signes qui, [V, 131] avec l'évolution, semblent arbitraires, étaient en partie des images à l'origine - est cependant, et justement eu égard à la langue, d'une importance considérable, comme on peut le montrer par l'exemple des Mexicains et des Péruviens.

55- Les hiéroglyphes mexicains avaient atteint un degré non méprisable de perfection ; ils conservaient manifestement la pensée en eux-mêmes parce qu'ils sont encore compréhensibles aujourd'hui, ils se sont aussi de temps à autre nettement distingués de simples images. Car même si, par exemple, le concept de la conquête est représenté en eux d'ordinaire par le combat de deux guerriers, on trouve bien également, avec son paraphe, le roi assis, puis des armes formées comme des trophées et enfin le symbole de la ville conquise, ce qui ensemble donne la phrase précise : le roi a conquis la ville, phrase qui est exprimée de manière beaucoup plus claire que la célèbre inscription saïte ${ }^{33}$, qui est d'habitude la seule à être citée où, dans l'héritage de l'Antiquité, se sont maintenus en même temps la signification et le signe. On voit aussi, à partir de ce qui vient d'être dit, que, chez les Mexicains, les moyens d'écrire des noms ne manquaient pas et qu'ils étaient ainsi sur la voie de posséder des signes phonétiques dans le genre de ceux des Chinois. Néanmoins il est très douteux que la hiéroglyphique mexicaine soit jamais devenue une véritable écriture ${ }^{34}$.

56- Car on ne peut qualifier d'écriture véritable que celle qui indique des mots déterminés en une suite déterminée, ce qui, même sans alphabet, est possible, à l'aide de signes conceptuels et même à l'aide d'images. Si au contraire on appelle écriture, dans une compréhension élargie, toute communication de pensées qui se produit à l'aide de sons, c'est-à-dire par laquelle celui qui écrit pense aux mots et que le lecteur traduit en mots, même si ce ne sont pas les mêmes (une définition sans laquelle il n'y aurait aucune frontière entre l'image 
zwischen diesen beiden Endpunkten ein weiter Raum für mannigfaltige Grade der Schriftvollkommenheit. Diese hängt nemlich davon ab, inwieweit der Gebrauch die Beschaffenheit der Zeichen mehr, oder weniger an bestimmte Wörter, oder auch nur Gedanken gebunden hat, und mithin die Entzifferung sich mehr, oder weniger dem wirklichen Ablesen nähert und in diesem Raum, ohne den Begriff wahrer Schrift zu erreichen, allein auf einer Stufe, die sich jetzt nicht mehr bestimmen lässt, scheint auch die Mexicanische Hieroglyphenschrift stehen geblieben zu seyn. Ob man z.B. Gedichte, von welchen es berühmte und namentlich [132] angeführte gab, hieroglyphisch aufbewahren konnte? da die Poesie einmal unwiderruflich an bestimmte Worte in bestimmter Folge durch ihre Form gebunden ist, lässt sich jetzt nicht mehr entscheiden. War es nicht möglich, so befanden sich die Peruaner hierin in einer vortheilhafteren Lage. Denn eine Schrift, oder ein Analogon derselben, das nicht die Gegenstände selbst darstellt, sondern mehr innerliches Gedächtnissmittel ist, kann sich, wenn auch weniger fähig, auf ein andres Volk, oder eine entfernte Zeit überzugehen, der Sprache ganz genau anschliessen. Indess darf man freilich nicht vergessen, dass ein Volk, welches sich einer solchen Schrift in solchem Sinne bedient, nicht sowohl wirklich eine Schrift besitzt, als vielmehr nur den Zustand, ohne Schrift auf das blosse Gedächtniss verwiesen zu seyn, durch künstliche Mittel in hohem Grade vervollkommnet hat. Das aber ist gerade der wichtigste Unterscheidungspunkt in dem Zustande mit und ohne Schrift, dass in dem ersteren das Gedächtniss nicht mehr die Hauptrolle in den geistigen Bestrebungen spielt.

57- Welches indess auch die Vorzüge und Nachtheile jedes dieser beiden Schriftsysteme seyn mochten, so genügten sie den Nationen, welche sie sich angeeignet hatten; sie hatten sich einmal an dieselben gewöhnt, und jedes, vorzüglich aber das Peruanische, war sogar in die Verfassung des Staats, und die Art seiner Verwaltung verwebt. Es ist daher nicht abzusehen, wie eins dieser Völker von selbst auf Buchstabenschrift gekommen seyn würde; die Möglichkeit lässt sich allerdings nicht bestreiten. Das Beispiel Aegyptens zeigt die nahe Verwandtschaft von Laut-Hieroglyphen und Buchstaben, und aus der graphischen Darstellung der Verschlingungen der Knotenschnüre konnten Zeichen entstehen, die in der Gestalt den Chinesischen glichen, sich aber phonetisch behandeln liessen. Es hätte aber dazu eine ähnliche geistige Anlage gehört, als die Aegyptier schon so frühe verriethen, dass auch die älteste Ueberlieferung sie uns nicht anders darstellt, und es ist allemal ein ungünstiges Zeichen für die künftige Entwicklung einer Nation, wenn sie, ohne dass jene Anlage zugleich ans Licht tritt, schon einen so bedeutenden Grad der Cultur, und so mannigfache und feste gesellschaftliche Formen erreicht, als dies in Mexico und Peru der Fall war. Vermuthlich hätte man sich in beiden Reichen, so wie heute in China, den Gebrauch der Buchstabenschrift anzunehmen geweigert, wenn er sich freiwillig, und nicht auf dem nöthigenden Wege der Eroberung dargeboten hätte.

58- [133] So wie ich versucht habe, bei den grammatischen Formen zu zeigen, dass auch blosse Analoga ihre Stelle vertreten können, ebenso ist es mit der 
et l'écriture), il se trouve entre ces deux extrêmes un grand espace pour de multiples degrés de perfection de l'écriture. Cette perfection dépend en effet de la mesure selon laquelle l'usage a lié la nature des signes à des mots plus ou moins déterminés ou bien seulement à des pensées, et par conséquent du fait que le déchiffrage s'approche plus ou moins de la véritable lecture ; c'est dans cet espace que semble être restée l'écriture hiéroglyphique mexicaine, sans atteindre le concept de la vraie écriture, mais à un niveau que l'on ne peut plus définir aujourd'hui. On ne peut plus aujourd'hui savoir si l'on pouvait par exemple [V, 132] conserver par des hiéroglyphes des poésies, dont on citait par leur nom des spécimens célèbres, puisque la poésie est incontestablement liée, par sa forme, à des mots déterminés dans une suite déterminée. Si ce n'était pas possible, les Péruviens se trouvaient alors dans une situation plus avantageuse. Car une écriture, ou bien un analogue, qui ne représente pas elle-même les objets, mais qui est plutôt un procédé mnémonique interne, peut se transmettre à un autre peuple (même moins doué) ou à une époque éloignée et se rattacher à la langue de manière exacte. Néanmoins, on ne doit pas oublier qu'un peuple qui se sert d'une telle écriture à une telle fin ne possède pas vraiment une écriture, mais qu'il a plutôt perfectionné à son plus haut degré, par un moyen artificiel, l'état où, en l'absence d'écriture, on doit s'en remettre à la mémoire. Mais justement, la différence la plus importante entre une situation où l'on possède l'écriture et celle où on ne la possède pas, c'est que dans la première, la mémoire ne joue plus le rôle principal dans les efforts de l'esprit ${ }^{35}$.

57- Quels que soient néanmoins les avantages et les inconvénients de chacun de ces deux systèmes d'écriture, ils suffisaient aux nations qui se les étaient appropriés ; elles s'étaient habituées à ces systèmes et chacune de ces écritures, la péruvienne davantage cependant, se trouvait même enchâssée dans la constitution de l'état et dans son mode d'administration. C'est pourquoi on ne peut guère imaginer comment l'un de ces peuples aurait pu en venir de lui-même à l'écriture alphabétique; on ne peut toutefois en contester la possibilité. L'exemple de l'Égypte montre la proche parenté entre les hiéroglyphes sonores et les lettres de l'alphabet; et de la représentation graphique que forment l'entrelacement des cordelettes à nœuds pouvaient naître des signes, qui, dans leur forme, ressemblaient à ceux des Chinois, mais qui pouvaient être traités phonétiquement. Mais il aurait fallu en plus une disposition spirituelle semblable à celle que les Égyptiens ont manifestée tellement tôt que la tradition la plus ancienne ne nous la représente pas autrement; et c'est de toute manière un signe défavorable pour l'avenir d'une nation si elle atteint un degré aussi significatif de culture et des formes sociales aussi variées et constantes que ceux que l'on rencontrait au Mexique et au Pérou, sans que cette disposition se manifeste. Dans ces deux empires, on aurait probablement refusé, comme aujourd'hui en Chine, d'adopter l'usage de l'alphabet, s'il s'était présenté comme un choix libre et non par les voies contraignantes de la conquête.

58- [V, 133] Il en va de l'écriture comme des formes grammaticales, à propos desquelles j'ai tenté de montrer que même de simples analogues peuvent les 
Schrift. Wo die wahre, der Sprache allein angemessne fehlt, können auch stellvertretende andre alle äusseren, und bis auf einen gewissen Grad auch die inneren Zwecke und Bedürfnisse befriedigen. Nur die eigenthümliche Wirkung jener wahren und angemessnen, so wie die eigenthümliche Wirkung der ächten grammatischen Form, kann nie und durch nichts ersetzt werden; sie liegt aber in der inneren Auffassung und der Behandlung der Sprache, in der Gestaltung des Gedanken, in der Individualität des Denk- und Empfindungsvermögens.

59- Wo jedoch solche stellvertretende Mittel (da dieser Ausdruck nunmehr verständlich seyn wird) einmal Wurzel gefasst haben, wo der instinctartig in der Nation auf das Bessere gerichtete Sinn nicht ihr Emporkommen verhindert hat, da stumpfen sie diesen Sinn noch mehr ab, erhalten das Sprach- und Gedankensystem in der falschen, ihnen entsprechenden Richtung, oder geben ihm dieselbe, und sind nicht mehr zu verdrängen, oder ihre wirkliche Verdrängung übt nun die erwartete heilsame Wirkung viel schwächer und langsamer aus. Wo also die Buchstabenschrift von einem Volke mit freudiger Begierde ergriffen und angeeignet werden soll, da muss sie demselben früh, in seiner Jugendfrische, wenigstens $\mathrm{zu}$ einer Zeit dargeboten werden, wo dasselbe noch nicht auf künstlichem und mühevollem Wege eine andre Schriftgattung gebildet, und sich an dieselbe gewöhnt hat. Noch weit mehr wird dies der Fall seyn müssen, wenn die Buchstabenschrift aus innrem Bedürfniss, und geradezu ohne durch das Medium einer andren hindurchzugehen, erfunden werden soll. Ob dies aber wirklich jemals geschehen seyn mag, oder so unwahrscheinlich ist, dass es nur als eine entfernte Möglichkeit angesehen werden darf? darauf behalte ich mir vor, bei einer andren Gelegenheit zurückzukommen. 
remplacer. Là où manque la vraie écriture, la seule conforme à la langue, des remplaçants peuvent aussi, autrement, satisfaire à tous les buts et besoins extérieurs et, jusqu'à un certain point, aussi à ceux qui sont intérieurs. Seulement l'effet particulier de l'écriture vraie et conforme, tout comme l'effet particulier de la vraie forme grammaticale, ne peut jamais être remplacé par quoi que ce soit ; cet effet se ressent dans la compréhension intérieure et dans le traitement de la langue, dans la formation des pensées, dans l'individualité de la faculté de penser et de sentir.

59- Là où, cependant, de tels moyens de remplacement (puisque cette expression sera désormais compréhensible) ont pris racine, là où, dans la nation, le sens instinctivement dirigé vers le meilleur n'a pas empêché leur succès, les moyens de remplacement émoussent ce sens encore plus, maintiennent le système de la langue et de la pensée dans la mauvaise direction, celle qui correspond à ces moyens, ou ils lui donnent cette direction et on ne peut plus les évincer, ou alors leur éviction effective n'exerce l'action salutaire attendue que bien plus faiblement et lentement. Là où, donc, l'écriture alphabétique sera saisie et assimilée par un peuple avidement et avec joie, celle-ci s'offrira tôt à lui, dans la fraîcheur de sa jeunesse, au moins à un moment où il n'aura pas encore forgé, par des voies artificielles et pleines de difficultés, une autre forme d'écriture à laquelle il se sera habitué. Ce sera encore davantage le cas si l'écriture alphabétique est inventée à cause d'un besoin intérieur, sans passer par le médium d'une autre écriture. Quant à savoir si tout ça a jamais pu réellement se produire, ou bien si c'est si invraisemblable que l'on ne puisse le considérer que comme une vague possibilité, je me réserve le droit d'y revenir à une autre occasion.

\section{NOTES}

1. Pour cette traduction, j'ai bénéficié de la relecture et des judicieux conseils de Jürgen Trabant, que je remercie chaleureusement. Avec ceux d'Henri Meschonnic, ses travaux ont joué un rôle important dans mon intérêt pour l'œuvre de Humboldt et ma compréhension de celle-ci. Une partie des annotations de la présente traduction s'inspire d'ailleurs de celles qu'il a faites dans son édition des discours tenus par Humboldt à l'Académie des sciences de Berlin (Humboldt W. 1994). Je remercie également la fondation Alexander-von Humboldt, dont le soutien m'a permis de séjourner à Berlin et d'y mener les recherches nécessaires à la réalisation de ce travail.

2. Humboldt renvoie ici aux découvertes toutes récentes de Jean-François Champollion le jeune qui, en 1822, venait de déchiffrer la pierre de Rosette et de prouver l'existence de hiéroglyphes à valeur phonétique. Humboldt a entretenu une importante correspondance avec Champollion, maintenant intégralement publiée dans l'ouvrage de Markus Messling (2008).

3. Trabant (dans Humboldt W. 1994 : 254) observe que Humboldt étend ici à l'écriture sa critique d'une vision de la langue comme « signe arbitraire » (« willkürliches Zeichen », GS IV : 29 ; Humboldt W. 2000 : 105), sur laquelle il revient d'ailleurs aux $\$ 9-10$. Il est clair que cette critique n'équivaut pas à quelque défense d'une iconicité originaire et naturelle des langues, ni à un rejet complet de l'arbitraire linguistique (voir l'entrée « willkürliches Zeichen » dans le glossaire ci-dessous). Dans le cas de l'écriture, Humboldt ne souhaite pas montrer que «les lettres, en tant que phénomènes matériels, sont des "images" visuelles des phonèmes ", mais plutôt soulever la question générale de savoir s'il est indifférent que l'écriture rende ce qu'on appelle, depuis Martinet, les unités de deuxième articulation (phonétiques) ou celles de la première (sémantiques). Les lettres sont en réalité des «images de leur forme [des phonèmes], de leur unité 
fonctionnelle, ce qui signifie qu'à chaque phonème en tant qu'unité distincte des autres phonèmes, correspond en principe une lettre distincte des autres lettres » (Trabant dans Humboldt W. 1994 : 254).

4. En allemand : geistige Tätigkeit. Il ne faut pas donner à « spirituel» un sens religieux. Voir à ce sujet l'entrée « Geist, geistig, Geistigkeit » dans le glossaire ci-dessous.

5. «L'élaboration la plus fine de la langue », pour Humboldt, c'est la littérature ou, plus généralement, ce qui s'écrit. Trabant renvoie ici à « Poesie und Prosa », GS VII : 206 et suiv. (trad. française Humboldt W. $1974: 358$ et suiv.).

6. Ces mémoires sont Ueber das vergleichende Sprachstudium in Beziehung auf die verschiedenen Epochen der Sprachentwicklung (1820; GS IV : 1-34; trad. française : Sur l'étude comparée des langues dans son rapport aux différentes époques du développement du langage, Humboldt W. 1999) et Ueber das Entstehen der grammatischen Formen und ihren Einfluss auf die Ideenentwicklung (1820; GS IV : 285-313; trad. française: Sur la naissance des formes grammaticales et leur influence sur le développement des idées, Humboldt W. 2000 : 64-111).

7. Je traduis ainsi «Figurenschrift», un terme par lequel Humboldt désigne une idéographie qui, au contraire de la «Bilderschrift» (écriture en images), transcrit les unités de première articulation par des signes non iconiques. Humboldt emploie toute une série de composés avec le morphème -schrift pour désigner les différentes formes d'écriture; il a décrit la terminologie qu'il emploie dans un texte antérieur à celui-ci, Ueber den Zusammenhang der Schrift mit der Sprache (Sur le rapport de l'écriture avec la langue ; $G S$ V : 1-106). On se reportera au glossaire, où j'explique la terminologie française que j'ai adoptée, en la faisant suivre de la traduction d'un extrait de Ueber den Zusammenhang der Schrift mit der Sprache.

8. Le terme allemand est Gesetzmäßigkeit, forgé à partir de gesetzmäßig, que l'on définit par « conforme à la loi » ou « suivant une loi interne ». Pierre Caussat a traduit ce terme par « légalité » dans L'introduction à l'œeuvre sur le Kavi (Humboldt W. 1974 : 200, 201, 251, 272, etc.). Plusieurs autres commentateurs recourent également à cette traduction.

9. Les trois propriétés de l'écriture alphabétique que Humboldt énumère ici, soit isoler et inventorier les phonèmes, les classer et montrer leurs modes de liaison correspondent aux trois parties fondamentales d'une description phonologique. De là, il apparaît clair que l'invention de l'alphabet repose sur une analyse phonologique préscientifique, comme l'explique Trabant (dans Humboldt W. $1994: 254$ ).

10. Humboldt emploie parfois «Laut» ou «Ton» ('son') pour désigner le mot entier, utilisant «Lautelement » pour parler plus précisément des phonèmes. Mais ici, «chaque son » («jeder Laut») renvoie bien au phonème. Par ailleurs, Humboldt et ses contemporains désignaient très souvent le phonème par Buchstabe (lettre), ce qui créait une confusion terminologique qui fut à bon droit critiquée. Mais comme le fait observer Trabant (dans Humboldt W. 1994 : 255), l'imprécision terminologique trouvait une certaine justification dans le fait que les lettres correspondaient, dans le meilleur des cas, aux phonèmes.

11. L'intuition d'une analyse phonologique sous-jacente à l'écriture atteste d'une conscience de la langue qu'on appellerait aujourd'hui «métalinguistique », conscience que favorise l'écriture. Humboldt montre que cette intuition, comme tout autre sentiment métalinguistique, agit en retour sur la langue : elles sont donc réflexives et appartiennent au fonctionnement de la langue elle-même (voir Trabant dans Humboldt W. $1994: 255$ ).

12. Sur Artikulation et Gliederung, voir notre glossaire.

13. Humboldt propose ici, plus de cent ans avant Trubetzkoy (1939), une première ébauche de phonologie, comme l'explique Trabant : "Ceci n'est rien de plus ni rien de moins que l'hypothèse fondamentale qui sous-tend le concept de phonème aujourd'hui valide : un phonème ne peut pas être défini seulement par sa qualité physique, c'est-à-dire ses propriétés articulatoires ou acoustiques. Que tel ou tel segment précis d'une suite de sons qui est physiquement un continuum doive être pris pour $u n$ son, on ne peut le dire que d'après 1'“intention" ou le "résultat". C'est-à-dire que la segmentation n'est possible que lorsqu'on peut constater qu'une partie du continuum est fonctionnelle, qu'elle a une fonction distinctive dans la signification, qu'elle peut "produire immédiatement des concepts en résonant". Par conséquent il n'est pas non plus possible de "ramener à un concept sensible général" la différence entre, par exemple, $/ \mathrm{p} /$ et $/ \mathrm{k} /$, cette différence ne se laisse constater que de manière fonctionnelle à l'intérieur d'une langue définie et non pas justement de manière générale. Il est en effet possible que la différence physique et articulatoire ne fonctionne pas comme différence phonologique dans une autre langue. » (Trabant dans Humboldt W. $1994: 255)$.

14. Humboldt reprendra cet exemple des sourds pour illustrer le caractère « intellectuel » de l'articulation dans les trois grands essais de maturité, soit Grundzüge des allgemeinen Sprachtypus (GS V : 376-377), 
Ueber die Verschiedenheiten des menschlichen Sprachbaues (GS VI: 152-154) et Ueber die Verschiedenheit des menschlichen Sprachbaues (GS VII : 66), en français : Humboldt W. 1974 : 205-206).

15. En allemand : Geistigkeit : ce substantif n'a pas de connotation religieuse en allemand. Voir l'entrée « Geist, geistig, Geistigkeit » dans le glossaire ci-dessous.

16. Le shloca (ou śloka) est une strophe héroïque de deux vers de seize syllabes, eux-mêmes composés de deux hémistiches de huit syllabes. Il est utilisé dans les grands poèmes épiques indiens comme le Mahabharata et le Ramayana. Humboldt, qui s'est livré à l'étude du sanskrit au cours des années 1820, connaissait très bien ce vers pour avoir traduit d'importants extraits de la Bhagavad-Gita, en essayant d'en respecter la métrique et le rythme (voir GS V : 197). Ce travail constitue une des bases des deux exposés sur la littérature et la philosophie indienne qu'il présentera à l'Académie des sciences de Berlin en 1825 et en 1826, Ueber die unter dem Namen Bhagavad-Gîtâ bekannte Episode des Mahâ-Bhârata I et II (ibid. : 190-232 et 325-354; Sur l'épisode des Mahabharata connu sous le titre de Bhagavad-Gita).

17. Sur les liens entre poésie et musique, voir aussi le chapitre «Caractère des langues. Poésie et prose » dans Humboldt W. 1974 : 348-349 ; « Charakter der Sprachen. Poesie und Prosa », GS VII : 195-196.

18. La flexion constitue en effet pour Humboldt le représentant par excellence de ce qu'il appelle des formes grammaticales « au sens propre et véritable» (Humboldt W. 1999: 80; «im wahren und eigentliche Verstande », GS IV : 286) ou, comme ici plus loin, au $\S 44$, « formes grammaticales authentiques » («ächte grammatische Formen », GS V : 124). Il s'agit de formes qui dénotent la valeur grammaticale sans avoir d'autre contenu sémantique : « les mots désignant la forme n'ont plus une signification accessoire qui les trouble, mais sont de pures expressions de rapports » (GS IV : 306 ; Humboldt W. 1999 : 96). Ces désignations grammaticales, en mettant au jour certains rapports, rendent manifeste « la forme de la pensée » (voir ici même au §10). L'écriture alphabétique de son côté est celle qui, mieux que toute autre, soutient cette manifestation, parce qu'elle montre elle-même les composants de la flexion. La flexion et l'écriture alphabétique sont en interaction réciproque, comme on le voit ici. Cette réflexion s'inscrit dans la suite du traité Ueber das Entstehung der grammatischen Formen/Sur la naissance des formes grammaticales (GS IV : 1-34 ; Humboldt W. 1999). La pensée de Humboldt sur les formes grammaticales évoluera considérablement par la suite, notamment à la faveur de ses échanges avec Abel-Rémusat sur le chinois. Sur cette question, on consultera avec profit l'ensemble du dossier préparé par Jean Rousseau \& Denis Thouard (Humboldt W. 1999).

19. Humboldt fait ici référence à l'un des systèmes d'écriture les plus anciens de la Chine, employé dans les textes de divination. Cohen \& Peignot (2005: 54) décrivent ainsi les Pa-kouas et leur lien possible avec les cordelettes à nœuds, dont Humboldt parle également plus loin (aux $\$ 52$ et suiv.) : « Les premiers signes tracés évoquant des éléments du langage n'auraient pas été des dessins, mais des combinaisons de barres, peut-être elles-mêmes transcription d'un système de cordelettes à nœuds mentionné par la tradition. Le système pa-koua $[\mathrm{pa}-k w a]$ a été décrit avec huit formes consistant en groupes de trois lignes continues ou interrompues, se référant aux deux principes qui sont censés gouverner les choses. Ce système symbolique a survécu jusqu'à nos jours chez les devins à la mise en usage de la véritable écriture, issue de la pictographie. »

20. Les recherches faites depuis le milieu du $\mathrm{XX}^{\mathrm{e}}$ siècle sur les hiéroglyphes mexicains montrent que les hiéroglyphes des Mayas, à tout le moins, comportaient des éléments phonétiques : «Actuellement, la plupart des chercheurs mayisants s'accordent sur un type d'écriture logo-syllabique avec l'utilisation de compléments phonétiques, de déterminatifs sémantiques et d'une table d'environ 84 valeurs syllabiques de type CV. » (Davoust 2012 [2001] : 181).

21. Les hiéroglyphes étant peu commodes pour un usage courant, les Égyptiens ont créé deux formes d'écritures cursives, le hiératique (inventé dès l'Ancien Empire et pratiqué jusqu'à l'époque romaine) et le démotique (apparu au VII ${ }^{\mathrm{e}}$ siècle av. J.-C. et demeuré en usage jusqu'au V $\mathrm{V}^{\mathrm{e}}$ siècle apr. J.-C.). Malgré son nom (qui signifie « sacré » et lui a été donné par les Grecs à une époque tardive), le hiératique servit d'abord à tous les types de documents (documents administratifs, textes littéraires et scientifiques, écrits religieux, inscriptions sacrées). Le démotique servit d'abord exclusivement pour les textes profanes (détrônant le hiératique dans cet usage) et se répandit peu à peu aussi dans le domaine religieux (voir Vernus 2012 [2001] : 56).

22. En allemand : « künstlicher Bearbeitung des Erdbodens ». Humboldt désigne ici des «monuments » (voir note suivante) qui ne sont pas des bâtiments, mais des ouvrages façonnés à même le sol, comme, par exemple, des tumulus (« künstlichen Hügeln », Humboldt W. 2016a : 80 ; « Grabhügeln », ibid. : 83, 85), des terrasses («Terrassen », ibid. : 84), des conduites d'eau («Wasserleitungen », ibid. : 104), etc. Je remercie Ute Tintemann de m'avoir aidée à éclaircir ce passage. 
23. Le « voyage » en question est celui qui est relaté dans Humboldt A. 1816. Le relevé dont Humboldt parle dans ce paragraphe est l'ouvrage qu'on a pris l'habitude de nommer Monumente (Humboldt W. 2016a : 67-136; Monuments) : ce titre, qui ne vient pas de Humboldt lui-même, mais d'Eduard Buschmann (qui fut le secrétaire privé des deux frères Humboldt), fait écho à celui du livre d'Alexander, où Wilhelm a puisé la plus grande partie de son matériel. Le texte du relevé est inachevé et est demeuré longtemps inédit (à l'exception d'un court extrait, qui avait été repris par Leitzmann dans GS V : 24-30). Il fait partie d'un ensemble de travaux d'histoire de la civilisation que Humboldt voulait intégrer à son grand projet d'étude comparée des langues américaines et est maintenant publié sous le titre Monumente der Nationen Amerika's dans un volume où sont réunis plusieurs travaux comparatifs sur les langues américaines (Humboldt W. 2016a).

24. Dans sa Relation historique aux régions équinoxiales du Nouveau Continent, Alexander von Humboldt écrit que les langues américaines présentent « une analogie générale de structure », tout en n'ayant « aucun mot en commun » (Humboldt A. 1814-1825 : 477-478). Cette opinion fut apparemment partagée par la plupart des américanistes jusqu'au XX ${ }^{\mathrm{e}}$ siècle (voir Trabant 2012 : 79). Wilhelm von Humboldt de son côté a d'abord surtout parlé de la diversité des langues américaines, dans l'Essai sur les langues du nouveau continent de 1812 (GS III : 300-341 ; Humboldt W. 2017 : 35-69). Pendant la période où les langues américaines étaient devenues son principal centre d'intérêt (surtout entre 1823 et 1826), il a par contre longuement cherché leurs supposées lois communes, mais n'a pu les trouver, et c'est là, d'après Trabant, la raison principale pour laquelle il a abandonné son projet de livre sur ce sujet (voir Trabant 2012 : 97). Il laissera tomber dans ses études ultérieures ce type de perspective pour s'intéresser aux particularités des langues. Dans l'Introduction à l'œuvre sur le Kavi, il fait de nouveau des remarques sur la grammaire des langues américaines, mais il les présente cette fois dans leur individualité (voir ibid. : 101).

25. Le point de vue de Humboldt sur les langues et cultures d'Amérique souffre ici évidemment d'ethnocentrisme (voir ibid. : 90-94). Ses jugements sur les langues étaient liés à ses propres valeurs, au but qu'il leur assignait : l'une de ses interrogations portait sur les langues qui accompliraient le mieux la tâche de la formation de l'esprit par le langage. Il estimait certaines langues plus riches et raffinées et d'autres, plus rudimentaires. Il a, par contre, de nombreuses fois affirmé que l'on pouvait tout dire dans toutes les langues et que toutes étaient dignes d'une étude approfondie : « La langue, et pas seulement en général, mais chaque langue, même la plus pauvre et la plus fruste, est en elle-même et pour elle-même un objet digne de la réflexion la plus soutenue. » (GS VII : 602, ma traduction). Plus loin, il ajoute ceci : «L'étude des langues de la terre est ainsi l'histoire mondiale des pensées et des sentiments de l'humanité. Elle dépeint les humains dans toutes les zones et dans toutes les étapes de sa culture ; en elle rien ne doit manquer, parce que tout ce qui touche les humains, concerne aussi les humains de près. » (ibid. : 602-603, ma traduction). Un tel point de vue n'était pas du tout répandu à son époque. Chateaubriand, par exemple, écrivait ceci : «pour tuer le temps, il [Humboldt] apprenait toutes les langues et même tous les patois de la terre » (cité dans Trabant 2012 : 92). Messling consacre tout un chapitre à ce problème de l'ethnocentrisme chez Humboldt (Messling 2008 : 227-276).

26. Voir supra la note du $\S 35$.

27. Humboldt se fonde ici sur les travaux de Pickering (1820) et surtout de Morse (1822), qu'il mentionne notamment dans Inwiefern läßt sich der ehemalige Culturzustand der eingebornen Völker Amerikas aus den Ueberresten ihrer Sprachen beurtheilen? (GS V : 3 ; Humboldt W. 2016a : 35-63) et Untersuchungen über die amerikanischen Sprachen (GS V : 360; Humboldt W. 2016a : 149-170). Le géographe et théologien Jedidiah Morse fut mandaté en 1820 par le secrétaire à la Guerre pour aller collecter des renseignements sur la situation des différentes nations autochtones. Le rapport qu'il a publié est plutôt favorable à ces nations et riche en informations sur les différentes tribus; il fournit aussi un portrait intéressant de leurs coutumes et de leur culture et contient beaucoup d'informations sur leurs langues. Il contenait en particulier des discours des chefs de tribus autochtones, auxquels Humboldt renvoie dans plusieurs textes et lettres.

28. Dans Ueber den Zusammenhang der Schrift mit der Sprache, Humboldt explique que les Égyptiens distinguaient nettement entre les images au sens strict et celles qui sont utilisées comme signes d'écriture : «Cette séparation si décisive de l'écriture en images des images me semble extrêmement remarquable. Il se trouve, dans la marche du développement habituel de l'esprit humain, qu'un peuple, progressant sur le même chemin déjà emprunté une fois, atteint des perfectionnements graduels ; et ainsi l'art qui symbolise, qui imite la langue pouvait devenir toujours plus clair et défini. Mais chez les Égyptiens, on voit qu'un moment est survenu où l'on a reconnu que cette marche progressive ne pouvait jamais conduire à l'écriture, puisque le chemin n'était même pas le bon, et on a emprunté un nouveau chemin. L'écriture hiéroglyphique ne vient pas d'une imagerie améliorée, mais elle est un genre entièrement nouveau, un passage dans un 
système entièrement nouveau » (GS V : 44). Il revient sur cette question un peu plus loin (ibid. : 49-50) et fait certaines comparaisons entre les hiéroglyphes des Égyptiens et des Mexicains, mentionnant qu'on retrouve quelques cas, néanmoins, de séparation nette chez ces derniers, comme il le mentionne dans Ueber die Buchstabenschrift..., §55.

29. Humboldt tenait pour très instructifs les discours des chefs de tribus autochtones, non seulement sur le plan politique, mais également sur le plan linguistique. Il espérait en effet qu'ils pourraient le renseigner sur le caractère des langues indigènes : le matériel dont il disposait sur l'Amérique centrale et l'Amérique du Sud, essentiellement formé de vocabulaires et de grammaires, ne lui offrait rien sur ce plan. Dans un autre texte sur l'écriture (Ueber den Zusammenhang der Schrift mit der Sprache, 1823-1824), Humboldt affirme que «l'étude des langues ne peut être séparée de celle de la littérature, car dans la grammaire et le dictionnaire seul leur squelette mort [...] est visible» (ibid. : 33). Il reformule cette idée dans un essai plus tardif (Ueber die Verschiedenheiten der Sprachen und Ihren Einflu $\beta$ auf den Geistesentwicklung, 1827-1829; GS VI : 111-303) et ajoute alors que, lorsqu'on ne dispose pas, pour l'étude d'une langue, de littérature, d'écrits, il faut essayer d'obtenir des échantillons de parole (récits, discours) et déplore que les discours de chefs que l'on trouve dans le rapport Morse soient le plus souvent traduits (ibid. : 147-148). Son intérêt pour les discours dans les langues autochtones est sans doute le motif qui l'a incité à s'abonner au journal autochtone de l'histoire, The Cherokee Phoenix, publié par Elias Boudinot entre 1828 et 1834, qui contenait des textes en cherokee et en anglais. (voir Trabant dans Humboldt W. $1994: 256$; MuellerVollmer $1993: 61$ et 68 ).

30. Le travail annoncé ici n'a sans doute pas été mené à terme. On trouve quelques remarques sur les cordelettes à nœud dans un fragment antérieur à Buchstabenschrift, intitulé Inwiefern läßt sich der ehemalige Culturzustand der eingebornen Völker Amerikas aus den Ueberresten ihrer Sprachen beurtheilen? (GS V : 11-14). Humboldt emploie dans ce texte le mot «Quipo » (on dit plutôt aujourd'hui « quipu »), qui en quechua signifie à la fois « compte, nombre et nœud. » (Lavallée $2012: 198$ ).

31. Humboldt fait ici une note : « dans le quatrième livre de son History of America ».

32. Comme il le fait ici, Humboldt laissait ouverte dans Inwiefern la question de savoir si ces cordelettes pouvaient avoir été une écriture au sens propre, tout en manifestant un doute sérieux : «Quipos. Ils ne sont sans doute rien d'autre que des aide-mémoire et une sorte beaucoup plus perfectionnée de bâtons de comptage, puisqu'on les trouve mentionnés seulement dans les institutions politiques. S'ils étaient une écriture, ils pouvaient seulement être une écriture de pensées. En soi ça ne serait sans doute pas impossible. » (GS V : 12). Selon des recherches plus récentes (voir Haarmann 2001 ; Lavallée 2012), les quipus étaient des systèmes sophistiqués pour marquer, en particulier, des valeurs numériques, des opérations arithmétiques et des statistiques, mais ne formaient pas une écriture véritable : « sans précisions orales sur le contexte, les informations enregistrées dans un quipu n'avaient qu'une valeur limitée » (Haarmann $2001: 59$ ).

33. Il s'agit de l'inscription dont parle Plutarque dans Sur Isis et Osiris : « À Saïs, la statut assise d'Athéna, qu'ils identifient à Isis, porte cette inscription : "Je suis tout ce qui a été, qui est et qui sera, et mon voile (peplos), aucun mortel ne l'a encore soulevé". » (Sur Isis et Osiris, 9, 354c ; cité dans Hadot 2004 : 342) La légende du voilement d'Isis connut une grande fortune dans l'histoire et fut, en Allemagne, particulièrement importante à l'époque des Lumières, puis du premier romantisme: on la retrouve notamment chez Kant (dans la Critique du jugement), Schiller (dans les essais La mission de Moïse, Du sublime et dans le poème « L'image voilée de Saïs »), Novalis (Les disciples à Saïs). Voir Hadot 2004.

34. Coulmas écrit à ce sujet : «The Aztek system is a picture-word writing system in which the initial steps towards phonetization had been accomplished, but which never developed to a full-fledged system, however. It remained at the threshold of writing proper.» (Coulmas 1989: 31, cité par Trabant dans Humboldt W. $1994: 256$ ).

35. Trabant souligne l'importance des remarques de Humboldt sur la «psychodynamique de l'écriture, en particulier sur la relation entre la mémoire et l'écriture » (Trabant dans Humboldt W. 1994: 253) : «Le délestage de la mémoire accompli par l'écriture est la condition pour que l'intelligence soit libérée de la pure performance de mémorisation, l'écriture est ainsi également la condition de possibilité des efforts avancés de l'esprit, tels qu'ils se développent dans la prose. » (ibid. : 256). Il renvoie à "Caractères des langues. Poésie et Prose» dans l'Introduction à l'œeuvre sur le Kavi (GS VII : 207-208; Humboldt W. $1974: 359-360)$. 